\section{Recursos formales y constructivos en la arquitectura militar almohade de al-Andalus}

\section{Formal and building resources in the military almohad architecture from al-Andalus}

SAMUel MÁrquez Bueno

Yamur. Arquitectura y Arqueología, S.L. Málaga

Pedro Gurriarán Daza

Instituto de Estudios Campogibraltareños. Cádiz*

\section{Resumen}

El presente artículo trata sobre algunos aspectos especialmente característicos de la construcción militar almohade (Siglos XII y XIII), que venían a definir una imagen clara y propagandista del poderoso promotor que había detrás. En concreto, hablaremos de la terminación de los muros de hormigón de cal encofrado, puertas de acceso a las fortificaciones y torres poligonales y albarranas. Afrontaremos el trabajo mediante el estudio de diversos ejemplos, que nos permitirán rastrear, igualmente, la existencia de equipos de constructores itinerantes que cumplirían las órdenes de las autoridades almohades.

Palabras clave: Almohade. Murallas. Puertas de fortificaciones. Albarrana. Tapial.

\section{Abstract}

This paper deals with some featuring aspects of the almohad military construction ( $12^{\text {th }}$ and $13^{\text {th }}$ centuries), which define a clear and propagandistic image of its powerful developer. The finishing of concrete walls, accesses to fortifications and polygonal towers and albarranas (external towers) are here analysed. This paper is the result of studying several examples, which allow us to trace the existence of itinerant builders' teams working for the almohad authorities.

Key words: Almohad. Wall. Fortress gates. Albarrana (External tower). Tapial (Mud wall).

*yamursl@gmail.com

\section{INTRODUCCIÓN}

La progresión del movimiento almohade en la Península y su aceptación por los andalusíes no fue ni rápida ni uniforme. Prueba de ello es el cuarto de siglo que media entre las primeras operaciones militares, en 1147, y la sumisión de los mardanisíes, en 1172, en que se completó la unificación de al-Andalus bajo su autoridad. Durante ese lapso de tiempo se produjeron avances y retrocesos que incluso estuvieron a punto de dar al traste con el definitivo afianzamiento de su poder. Al fin y al cabo, la población local no dejó de percibir a los almohades como elementos extraños, hecho del que los africanos fueron plenamente conscientes. Por este motivo, los Unitarios siempre tuvieron una necesidad perentoria de legitimar su autoridad ante los andalusíes, aunque para ello tuvieran que desviar la atención de un importante escollo: la originalidad doctrinal, justificación y raíz del movimiento almohade, resultaba poco compatible con el tradicional malikismo imperante en al-Andalus. La apuesta de los norteafricanos consistió en hacer de la guerra santa su más visible seña de identidad, mostrándose a ojos de los musulmanes peninsulares como verdaderos campeones de la fe y la única respuesta posible y eficaz ante la agresión cristiana, para lo que también se abordó un programa de fortificación ambicioso de todo el territorio bajo su autoridad $^{1}$.

De la misma forma que el ideario doctrinal del estado almohade se reflejó en la arquitectura religiosa mediante la imposición y generalización de una estética novedosa y fácilmente reconocible ${ }^{2}$, la arquitectura militar también fue testigo de la creación de una imagen dinástica que plasmaba el mensaje de los nuevos señores. Lógicamente, debió existir un cuerpo de arquitectos, o una serie de alarifes «en nómina», al servicio del régimen almohade, que diseñase y ejecutase el concepto edilicio que los unitarios querían mostrar de su mensaje con un claro afán propagandista. La presencia de estos técnicos puede rastrearse a través de las crónicas que dan cuenta de cómo el

\footnotetext{
${ }^{1}$ El pensamiento imperante entre los primeros califas almohades es evidente en citas como ésta, atribuida a Ya'qūb al-Manșūr, «la huérfana es la península de alAndalus y los huérfanos los musulmanes que la habitan; tenéis que ocuparos de lo que allí conviene: elevar sus murallas, defender sus fronteras, entrenar a sus soldados [...]». Viguera Molíns, M. J., «La fuerza de la fe: La reacción almohade», La Arquitectura del Islam Occidental, Coord. R. López Guzmán, Ed. Lunwerg, Barcelona, 1995, p. 142.

${ }^{2}$ Se refiere esta cuestión con claridad en Cressier, P., «El patrimonio almohade de Almería", Los almohades. Su patrimonio arquitectónico y arqueológico en el sur de al-Andalus, Sevilla, 2004, p. 93.

${ }^{3}$ De ello se ocupa, por ejemplo, Jiménez Martín, A. "¿Quién diseñó la casa de Umm Salama?», Arquitectura en al-Andalus. Documentos para el siglo XXI, Barcelona, 1996, pp. 21 y 22.
} 
más reputado de ellos, Aḥmad b. Baso, dirigía a sus colegas en numerosas empresas constructivas de carácter oficial ${ }^{3}$. Por otro lado, el Bayān al-Mugrib refiere una interesante misión de rango estatal: la reconstrucción y repoblación de la ciudad de Beja, tras un calamitoso ataque portugués, en la que uno de los caídes designados ha de reclutar en Silves y otras partes del Algarve una legión de albañiles para ejecutar la obra referida ${ }^{4}$. Esta noticia, entre otras ${ }^{5}$, nos da pistas para suponer que los encargados de materializar las directrices marcadas por los alarifes, directamente vinculados a las autoridades almohades, eran un conjunto de cuadrillas de albañiles especializados, reclutadas de forma puntual para la ejecución de tal o cual obra.

Destaca, no obstante, y por encima de otras cuestiones, el grado de estandarización que alcanzaron en los sistemas constructivos empleados, sobre todo en la técnica del tapial ${ }^{6}$, como una muestra del interés por lograr la referida imagen estatal. El grado de conocimiento histórico y arqueológico que poseemos sobre las grandes obras de fortificación de Sevilla ${ }^{7}$, Cáceres ${ }^{8}$, Jerez de la Frontera ${ }^{9}$, Niebla $^{10}$ o Badajoz ${ }^{11}$, entre otras, nos ha permitido alcanzar un adecuado nivel de sistematización sobre los modos de construir en periodo almohade y extrapolar sus conclusiones al estudio de otras defensas que presentan similares características generales. Otras de las importantes lagunas que la arqueología debería resolver próximamente es el vacío consecuente que se deriva del desconocimiento de las técnicas de la arquitectura militar almorávide, toda

${ }^{4}$ Ibn Iḍārī, al-Bayān al-Mugrib, Trad. A. Huici Miranda, Tetuán, 1953, pp. 13 a 20 .

5 Ibidem, pp. 57, 58, 97 y 176. Ibn Şăhib al-Salā, Al-Mann bil-Imama, Trad. A. Huici Miranda, Valencia, 1969, pp. 22, 50, 149, 181, 182, 188, 190, 191, 195 a 204 .

${ }^{6}$ Por su carácter general, véase, Gurriarán Daza, P. y Sáez Rodríguez, A. J., "Tapial o fábricas encofradas en recintos urbanos andalusíes», Actas del II Congreso Internacional «La ciudad en al-Andalus y el Magreb», Granada, 2002, pp. 561 a 625.

${ }^{7}$ Véase sobre la autoría almohade de la cerca urbana hispalense, Valor Piechotta, M., La arquitectura militar y palatina en la Sevilla musulmana, Diputación Provincial de Sevilla, Sevilla, 1991, pp. 215 y 216; y, además, "Las defensas urbanas y palatinas», El uiltimo siglo de la Sevilla islámica (1147-1248), Sevilla, 1995 , p. 56

${ }^{8}$ Márquez Bueno, S. y Gurriarán Daza, P., «La muralla almohade de Cáceres: aspectos constructivos, formales y funcionales", Arqueología y Territorio Medieval, 10.1, Jaén, 2003, pp. 57 a 118.

${ }^{9}$ Se defiende un origen almohade de estas murallas en Menéndez Robles, M. L. y Reyes Téllez, F., «Estructuras defensivas de una ciudad almohade: Jerez de la Frontera", Actas del II Congreso de Arqueología Medieval Española (Madrid, 1987), tomo II, Madrid, 1987, pp. 766 a 772.

${ }^{10}$ Pérez Macías, J. A. et alii, «Las murallas de Madina Labla (Niebla, Huelva)», Actas I Congreso Internacional Fortificaciones en al-Andalus (Algeciras, noviembrediciembre, 1996), Ayto. de Algeciras, Algeciras, 1998, p. 351.

${ }^{11}$ Torres Balbás, L., "La alcazaba almohade de Badajoz», al-Andalus, VI, 1941, pp. 178 y 179. vez que algunas cronologías tradicionales se han retrasado a periodo muminí ${ }^{12}$. Por último, la arquitectura almohade y la coetánea pero rival mardanisí, bien estudiada en las dos últimas décadas, compartirán sistemas constructivos, pero diferirán en algunos aspectos morfológicos, como vemos por ejemplo, en el uso de torres poligonales en la primera y unas curiosas torres esquineras en la segunda $a^{13}$.

En resumidas cuentas, a la hora de abordar el estudio de la arquitectura militar almohade como manifestación estereotipada de un mensaje político y legitimador, podemos considerar dos grandes campos: por un lado, el análisis de la apariencia formal y epidérmica de la construcción en virtud de los restos que tenemos correctamente datados; y por otra parte, el relativo al conjunto de técnicas y procedimientos empleados para llevar a cabo la erección de la edificación. Así, es posible asociar el primer aspecto al mencionado cuerpo de alarifes directores, mientras que el segundo quedaría relacionado con las cuadrillas de albañiles especializados. No obstante, este planteamiento podrá ser matizado a lo largo de este artículo, donde incidiremos en estas cuestiones tras el estudio arqueológico de varias construcciones castrales almohades y el refrendo de las fuentes.

\section{HACIA UNA IMAGEN OFICIAL DE LA ARQUITECTURA MILITAR}

Como ya se ha avanzado en líneas anteriores, y en el contexto que nos ocupa, el aspecto final de una fortificación recién finalizada decía mucho acerca de sus promotores, los almohades. En este caso, muy preocupados en dejar clara su autoría mediante un lenguaje que distinguiese claramente sus obras de las inmediatamente precedentes; $y$ en ciertos aspectos, que las vinculase con la prestigiosa arquitectura del Estado Omeya andalusí (vid infra). Los elementos articuladores de la referida «imagen oficial» que hemos considerado abarcan tres grandes bloques de estudio: acabados superficiales de las construcciones de hormigón de cal ejecutadas con tapiales, torres representativas, y accesos monumentales.

\footnotetext{
${ }_{12}$ Por ejemplo, las defensas urbanas de Sevilla, Córdoba, Almería o Granada se habían identificado con un impuesto especial, conocido como $t a^{\prime} t i b$, que se establece en al-Andalus por los almorávides en 1125; Ibn Id̄ārī, Bayān al-Mugrib, nuevos fragmentos almorávides y almohades, Trad. A. Huici Miranda, Valencia, 1963 , pp. 170 a 172. Torres Balbás llega a incluir en esta lista a las obras de Niebla o Jerez de la Frontera. Torres Balbás, L., Ciudades hispanomusulmanas, Instituto Hispano-árabe de Cultura, Madrid, 1985, pp. 478 y 481.

${ }^{13}$ Consúltese el interesante estudio de Navarro Palazón, J. y Jiménez Castillo, P., "Arquitectura mardanisí», La Arquitectura del Islam Occidental, Coord. R. López Guzmán, Ed. Lunwerg, Barcelona, 1995, pp. 117 a 137.
} 


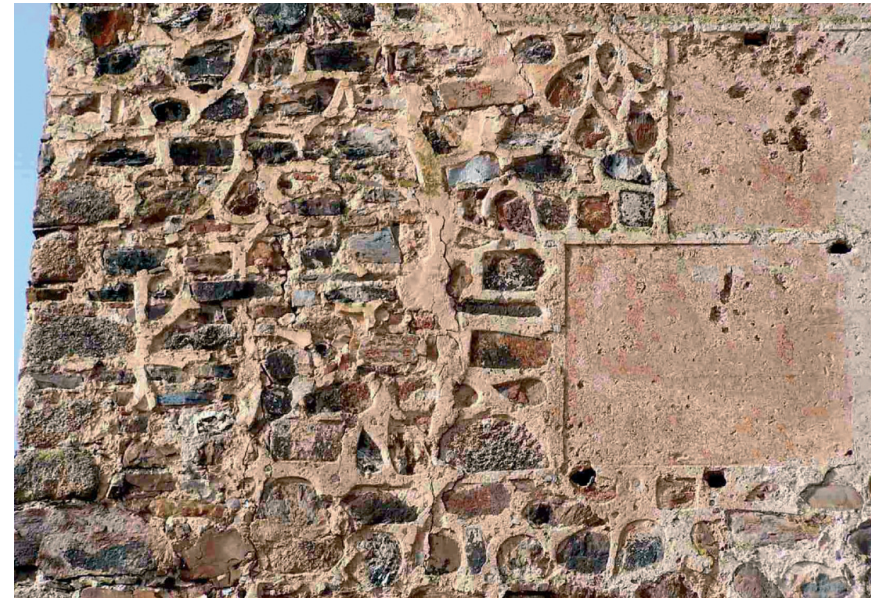

Fig. 1. Zona inferior de la Torre de los Pozos, en el recinto almohade de Cáceres, en la que destaca el acabado superficial con un encintado calizo que bordea los mampuestos esquineros y marca las hiladas de tapia

\subsection{Acabados superficiales}

El tratamiento epidérmico aplicado a la superficie de los cajones está íntimamente ligado a la protección de la misma frente a los agentes erosivos. Tal cuestión se revela tan antigua como la misma técnica de obra encofrada, por lo que la depuración y perfeccionamiento de la técnica irá aparejada al desarrollo de dicho tratamiento superficial, que evolucionará desde una solución meramente tectónica hacia unas funciones más estéticas en ciertos casos.

En período almohade se erigirán estructuras tanto enjalbegadas totalmente como en bruto, confiando en este último caso en la propia fortaleza del material hormigonado para resistir el desgaste. No obstante, el acabado aplicado a la superficie de los cajones que más predicamento tendrá será sin duda el recurso del encintado, debido al cual prácticamente todas las obras militares almohades mostrarán una apariencia similar, que de forma inevitable nos sugiere la existencia de un único promotor detrás de la ingente cantidad de fortificaciones erigidas en este período. Ya desde hace unos años, algunos investigadores han ido haciéndose eco de este tipo de obras encofradas y su uniformidad en sus trabajos ${ }^{14}$, llamando la atención sobre la incorrecta datación de muchas de las construcciones así terminadas que predominaba en la historiografía tradicional.

Puede ocurrir que la obra encofrada, como medida de protección y/o topográfica, se erija sobre un zócalo pétreo,

\footnotetext{
${ }^{14}$ Azuar Ruiz, R., "Aspectos simbólicos de la arquitectura militar almohade. El falso despiece de sillería y las bóvedas de arcos entrecruzados", Los almohades: problemas y perspectivas, Volumen I, Madrid, 2006, pp. 123 a 147. Azuar Ruiz, R. et alii, "El falso despiece de sillería en las fortificaciones de tapial de época almohade en al-Andalus», Actas del I congreso de Castellología ibérica, Palencia, 1994 , pp. 481 a 511.
}

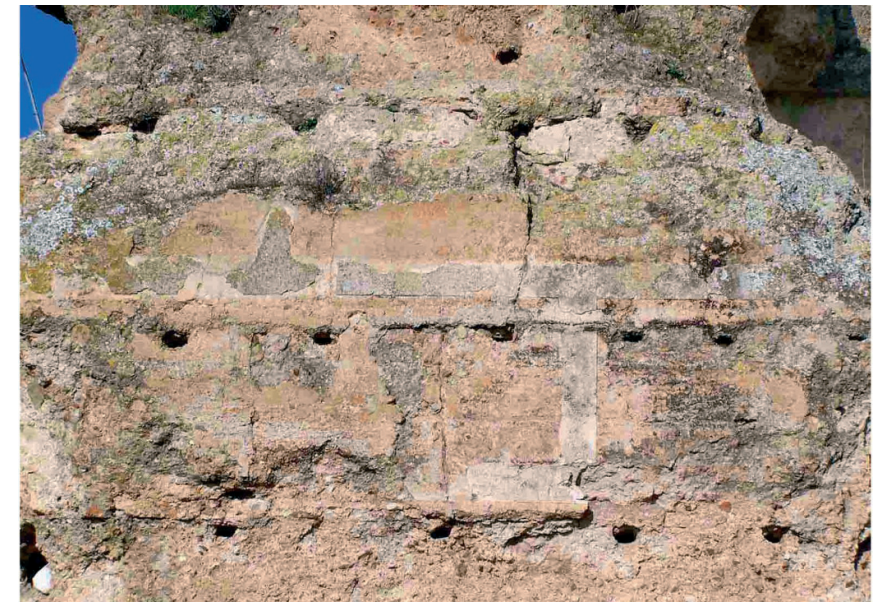

Fig. 2. Torre de la fortificación de El Vacar donde se aprecia la no coincidencia entre las líneas de mechinales y las cintas de mortero de cal

de sillares, mampuestos, o ambos materiales a la vez. En este caso, el mortero de cal se empleaba para tomar los elementos líticos y, a veces, para cubrirlos por completo. De forma opcional, sobre el mortero todavía fresco se podían trazar líneas incisas que simulasen piezas similares a las ocultas. En otras ocasiones, la cara exterior de los mampuestos se encintaba con dicho mortero adaptándose la cinta al contorno de los mismos, o inventando otras formas, tales como lágrimas (Fig. 1).

Por encima de la base se elevan las sucesivas hiladas de hormigón sobre las que se disponían las cintas de mortero de cal, con ligeras variaciones como veremos. Los ejemplos conservados muestran cómo su relieve oscila entre escasos milímetros y dos o tres centímetros, y su grosor abarca aproximadamente de los siete a los doce centímetros. Las cintas horizontales distan unas de otras la altura de la hilada correspondiente, $y$ en un principio se trazaban sobre la línea de las cabezas seccionadas de las agujas del encofrado, seguramente para proteger y disimular estos puntos vulnerables de la estructura del muro. Afirmamos que en un principio porque, en múltiples ocasiones, la faja no discurre por la referida línea sino unos centímetros por debajo o encima. Cabe reseñar el conocido ejemplo de El $\operatorname{Vacar}^{15}$, donde ya es excesiva la no correspondencia entre

\footnotetext{
15 Este castillo ha sido tradicionalmente identificado como obra califal, sobre todo tras el trabajo de Torres Balbás, L., "Arte hispanomusulmán hasta la caída del califato de Córdoba", España Musulmana hasta la caída del califato de Córdoba (711-1031). Historia de España, Dir. R. Menéndez Pidal, tomo V, Madrid, 1957, pp. 331 a 725. Azuar ya cita un origen posterior a lo omeya en Azuar Ruiz, R. et alii, «El falso despiece de sillería en las fortificaciones de tapial de época almohade en al-Andalus", Estudios de Historia y Arqueología medievales, XI, Universidad de Cádiz, Cádiz, 1996, p. 255, Córdoba de la Llave, R., «Fortificaciones Almohades de la provincia de Córdoba», Los almohades. Su patrimonio
} 
Fig. 3. Lienzo oriental del bastión de la Torre de los Pozos (Cáceres). Obsérvese el encintado del muro y enjalbegado de pretil y merlones

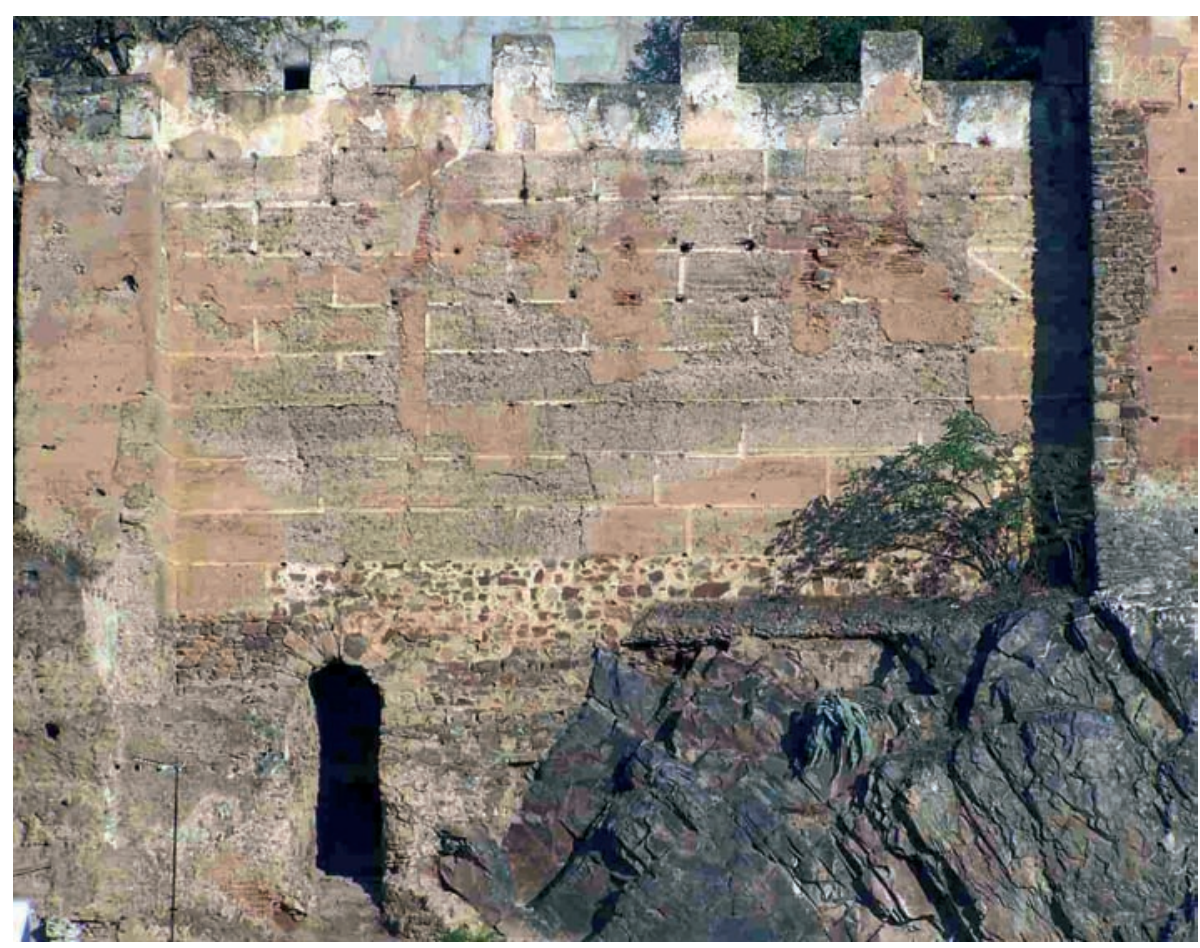

tales elementos, cumpliéndose así una función puramente estética aunque no tectónica en todos estos casos (Fig. 2).

También, solían ubicarse cintas verticales cuya misión era siempre decorativa y, en ocasiones, constructiva cuando discurrían sobre una junta vertical de obra que, como ya sabemos, a causa del empleo de los encofrados corridos podían producirse a largos intervalos. Recordemos cómo tales interrupciones en la erección de una hilada también se podían producir mediante un plano inclinado. En consecuencia, es lógico que en estos casos pueda disponerse la cinta inclinada sobre la junta oblicua, como se observa excepcionalmente en los recintos de Cáceres y Niebla (Fig. 3). En cualquier caso, estas fajas verticales o inclinadas no eran tan imprescindibles puesto que no protegían ningún elemento lignario. Prueba de ello es que en las fortificaciones de Cáceres, Alcácer do Sal y Sevilla se observan torres y lienzos encintados, desde su origen, sólo horizontalmente (Fig. 4). Por este motivo, las verticales podían disponerse libremente, de forma más aleatoria, o perfectamente isódomas; como se aprecia el primer caso en Játiva, Aroche, Paderne... y el segundo en Gibraltar, Niebla, El Vacar, Villena... Incluso, en ocasiones, en una misma fortificación se combinan las dos formas referidas, como vemos en Badajoz, Cáceres y Silves (Fig. 3).

arquitectónico y arqueológico en el sur de al-Andalus, Sevilla, 2004, pp. 124 y 125 propone una cronología almohade para el castillo de El Vacar, con la que comulgamos, dada la similitud edilicia existente con el resto de la producción almohade erigida con tapiales.
Un detalle importante apreciado en este recintos tan distantes como Cáceres y Játiva, es la aplicación de encintados en ambas caras de sus muros, mientras que en el resto de fortificaciones coetáneas que ostentan tales fajas sólo ha podido comprobarse su presencia en la cara externa, aunque sospechamos que esto se deba más bien a que han desaparecido ejemplos similares al extremeño y valenciano. No obstante, en obras posteriores, como la Chella meriní de Rabat, se constata la presencia de cintas en la cara interior de sus lienzos. En cuanto al empleo de éstas en quiebros de muro, se observa que, en ocasiones, las esquinas interiores eran recorridas por una sucesión de cintas verticales como puede verse en Aroche y Alcácer do Sal. Lo mismo ocurría con las esquinas exteriores, a pesar de subsistir únicamente el ejemplo portugués de Moura, por ser la zona más expuesta al desgaste.

Para concluir nuestra descripción haremos especial hincapié en el remate superior de la obra encofrada, en el que las hiladas correspondientes al pretil y los merlones eran completamente revocadas con una gruesa capa del mismo mortero de cal empleado en cintas y basamento. Hemos podido constatar fehacientemente esta solución en las cercas de Cáceres, Badajoz, Mértola, Silves, Niebla, Gibraltar, La Iruela y Bentomiz (Málaga; Fig. 3). También deberíamos citar el antemuro del tramo de la Macarena del recinto hispalense, y ciertas partes de las murallas de Córdoba, en los que se perciben vestigios. En otras obras militares donde se aprecian fajeados no ha sido posible 
comprobar la subsistencia del revoco sobre parapeto y merlatura, fundamentalmente porque éstos han desaparecido. De este modo, creemos que los ejemplos supervivientes, recién mencionados, son suficientes para este peculiar remate epidérmico como una práctica constructiva habitual. Es más, su cometido, al margen del estético, era puramente tectónico. En efecto, gracias a tales morteros se protegía la tâbiya de la acción del agua de lluvia que podía afectar a la estructura del muro filtrándose por sus partes altas más expuestas.

El desarrollo y evolución de los encintados desembocó en la aparición de motivos más complejos y elaborados. De los escasos restos subsistentes merece la pena detenerse en los del recinto almohade de Cáceres, por su relativo buen estado de conservación y su relevancia simbólica. Los vestigios aludidos se concentran en las caras norte y este de la albarrana de los Pozos. Como se verá a continuación, la disposición de tales cintas está íntimamente ligada a la naturaleza, forma y disposición de los materiales empleados. Por ello, antes de ofrecer una descripción de los motivos decorativos será necesario referir el proceso constructivo seguido en este bastión. Éste se cimienta sobre una irregular cresta rocosa, por lo que fue necesario crear una base plana, de material pétreo, para posibilitar la erección de los sucesivos cajones. Del total de once con que cuenta la torre, las esquinas orientales de los cinco primeros están reforzadas por bloques de la misma mampostería empleada en el zócalo, material inexistente en las siete hiladas superiores. Sobre la obra encofrada se dispusieron las consabidas fajas horizontales de mortero de cal, en algunos casos cubriendo la línea de mechinales y en otros ligeramente por encima. En cuanto a la parte lítica, se creó un encintado que remarcaba cada pieza, o un pequeño conjunto de ellas, potenciándose la apariencia de los mampuestos en vez de disimularla. Es importante aclarar cómo tales cintas se trazaron claramente definidas y con cierta gracia, tratando de dignificar un aparejo tan irregular y grosero. Por encima de esos refuerzos pétreos, se erigen tres hiladas en las que en la zona esquinera se dibujan, con el mismo mortero calizo, líneas que simulan envolver sillares y mampuestos que simplemente no existen. Así, se prolonga la apariencia de las hiladas inmediatamente inferiores, aunque en esta zona con una finalidad puramente estética. Finalmente, los cuatro hilos superiores fueron totalmente enjalbegados por el consabido mortero blanco. Al quinto y último, el correspondiente a los merlones y desaparecido en un momento indeterminado, le suponemos idéntico tratamiento epidérmico (Fig. 4). Se pueden señalar como similares a éstos los vestigios de acabados superficiales de lo

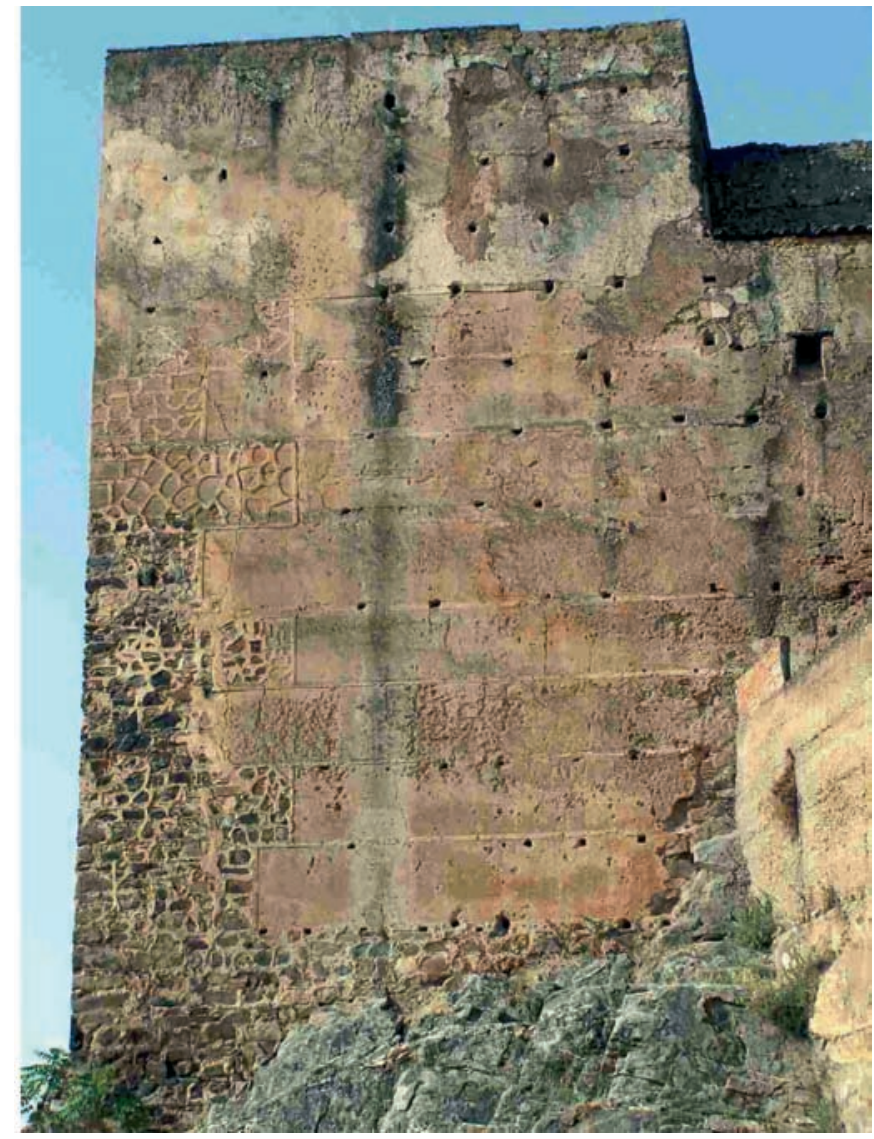

Fig. 4. Cara norte de la albarrana de los Pozos (Cáceres)

que queda de la torre de flanqueo de la Puerta de Yelves en la Alcazaba de Badajoz, y varias torres del flanco septentrional del recinto urbano de Niebla.

En el caso que nos ocupa, no sólo se trazaron cintas a modo de fajas, sillares o mampuestos, sino que también se utilizaron para crear estrellas de ocho puntas e inscripciones en cúfico ${ }^{16}$, como se aprecia en las fachadas este y norte de la albarrana, respectivamente (Figs. 5 y 6). Hasta ese momento, las únicas inscripciones de carácter oficial que se han identificado en arquitectura castrense andalusí son de carácter fundacional, nunca religioso. Precisamente, en la

\footnotetext{
${ }^{16}$ Existen estrellas similares en los muros del Castillejo de Monteagudo, aunque en este caso incisas. Navarro Palazón, J. y Jiménez Castillo, P., «El Castillejo de Monteagudo: Qasr ibn Sa'd», Casas y palacios de Al-Andalus (Siglos XII y XIII), Ed. J. Navarro Palazón, Barcelona, Lunwerg - El Legado Andalusí, 1995, p. 96 y figs. 36 y 54. También existen restos parecidas en la pequeña fortificación almohade de Salir, en el Algarve. Catarino, H. "Os castelos de taipa do período muçulmano no sul de Portugal: O exemplo de Salir (Loulé)", 1. ${ }^{\circ}$ Congresso de Arqueologia Peninsular (Porto, 12-18 de Outubro de 1993), Coord. por V. M. Oliveira Jorge, Vol. 4, 1994 , pp. 335 a 344. Varela Gomes, R., Silves (Xelb), uma cidade do Gharb al-Andalus: territorio e cultura, Trabalhos de Arqueologia, 23, Instituto Portugués de Arqueología, Lisboa, 2002, p. 120. Por último, señalar que en el lienzo este del Castillo de Gibralfaro de Málaga, ejecutado con tapiales en periodo nazarí, se localizan interesantísimas estrellas de ocho puntas realizadas en el mortero de cal que rodea puntualmente las piezas del zócalo de mampostería.
} 
Fig. 5. Una de las dos estrellas de ocho puntas conservadas en la faz oriental de la albarrana de los

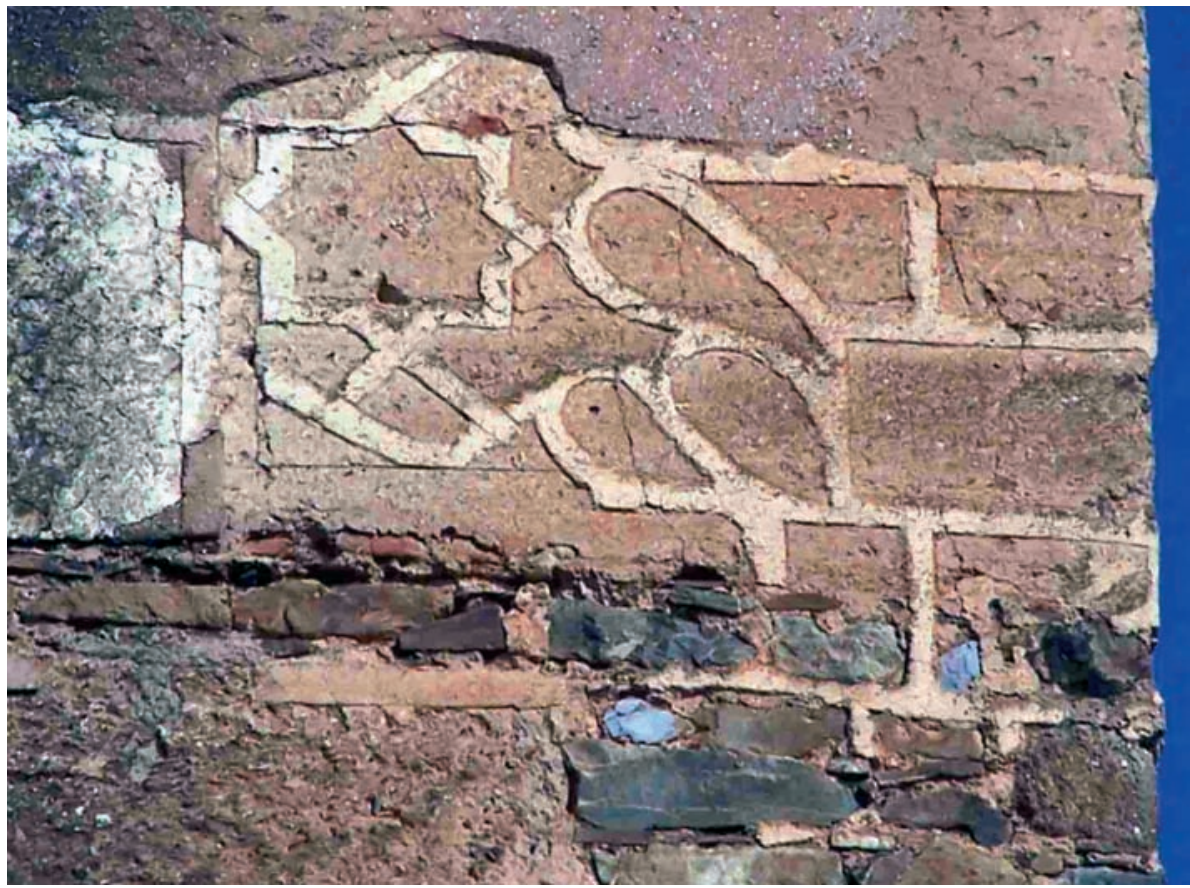

torre de los Pozos se documenta uno de los primeros ejemplos conocidos de epigrafía religiosa en una obra militar ${ }^{17}$. Si consideramos en su conjunto todos estos motivos de exorno, la torre en cuestión se nos revela como un muestrario de representaciones propagandísticas de una dinastía que ha de buscar su razón de ser y legitimidad en la yihâd o guerra santa.

Este tratamiento epidérmico, que hemos analizado pormenorizadamente y que constituye uno de los pilares de lo que hemos venido denominando «identidad corporativa», a causa de su difusión en la poliorcética almohade, se aplica precisamente en una obra documentada textualmente como de las más emblemáticas de los primeros tiempos de la dominación de los Unitarios en la Península, dirigida además por dos de sus más prominentes arquitectos: Ahmad b. Baso y al-Haŷŷ Yàī̌s, ambos andalusíes. Nos estamos refiriendo a la fortificación de Gibraltar, ordenada erigir en 1160 por el califa almohade según citan las fuentes ${ }^{18}$. El hecho de que en una obra emblemática, de fecha temprana y directamente vinculada al poder central, figure el acabado superficial descrito, y en el que además no se aprecian los típicos titubeos de la búsqueda y consolidación de las fórmulas más adecuadas para proteger los cajones, podría interpretarse como indicador de que semejante tratamiento ya se empleaba en fechas anteriores, y que fueron los almohades los que lo generalizaron en

${ }^{17}$ Se analiza este ejemplo y se comentan paralelos conocidos en Márquez Bueno, S. y Gurriarán Daza, P., op. cit., 2003, pp. 91 y 92.

${ }^{18}$ Ibn Șāhib al-Salā, op. cit., 1969, pp. 21 a 23. toda la poliorcética posterior, enfatizando sus valores estéticos y haciéndolos propios. Semejante incremento del

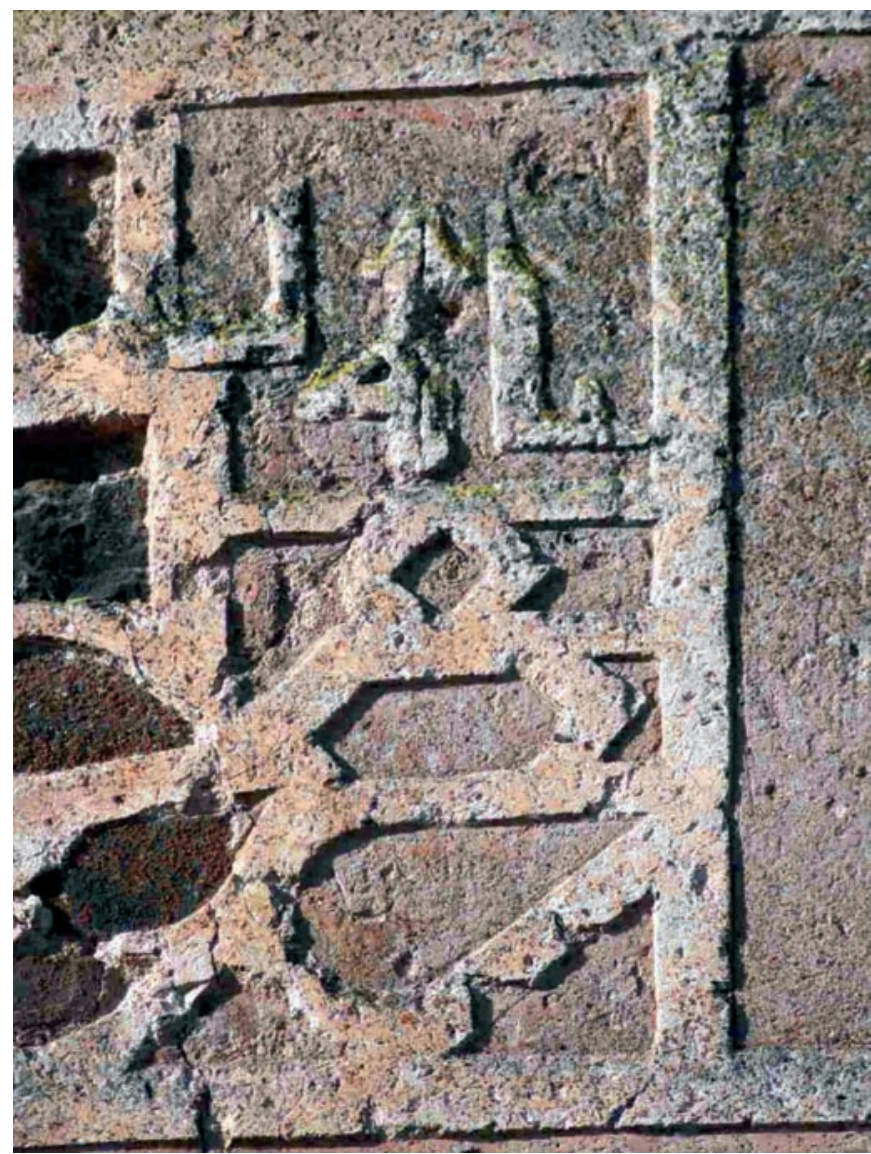

Fig. 6. Fragmento de inscripción cúfica en la cara septentrional de la albarrana de los Pozos (Cáceres) 
valor estético podría reflejarse en la anteriormente referida pérdida de función tectónica vista en el ejemplo del recinto de El Vacar, en el que la no correspondencia entre cintas e hiladas es evidente. Por otra parte, la apropiación por los almohades del efecto estético de obra encintada se manifiesta en su evolución y uso simbólico vistos claramente en el ejemplo de la Torre de los Pozos de Cáceres.

\subsection{Torres representativas}

Bajo este epígrafe hemos querido referirnos a dos tipos de torre militares: las albarranas y las de trazado poligonal. A pesar de que la existencia de semejantes tipologías se documenta desde épocas anteriores, puede atribuirse a los almohades su difusión y generalización. El carácter simbólico de estas torres queda patente en la medida en la que es posible cuestionar su origen como simple elemento poliorcético ${ }^{19}$. En el caso de las poligonales, algunos autores han interpretado su forma como la transposición de una torre cilíndrica, que al erigirla mediante el empleo de encofrados sencillos, adoptaría una forma poligonal (Fig. 7) ${ }^{20}$. Además, se suele justificar su habitual emplazamiento en las esquinas de los recintos, cumpliendo una función análoga a las de planta circular, sin ángulos muertos. Tal ubicación se corrobora en algunos casos: valga el ejemplo de las dos octogonales de Jerez de la Frontera y otro par de Niebla, que definen dos claros vértices de la planta de sus respectivas fortificaciones (Fig. 8). En Cáceres, una octogonal albarrana se emplaza en el ángulo suroeste del recinto, sin embargo, en el mismo existe otra octogonal exenta que no flanquea ningún quiebro significativo de muro ${ }^{21}$. Lo mismo se puede constatar en Écija ${ }^{22}$ y Andujar ${ }^{23}$, con múltiples albarranas octogonales documentadas, algunas en esquina y

\footnotetext{
${ }^{19}$ Se proponen argumentos en la misma línea en Cooper, E. «Desarrollo de la fortificación tardomedieval española", Mil anos de Fortificaçōes na Península Ibérica e no Magreb, Palmela, 2002, p. 673. Acién Almansa, M., "La fortificación en al-Andalus", La arquitectura del Islam occidental, Barcelona, 1995, p. 40 se refiere el carácter simbólico de las torres poligonales.

${ }^{20}$ Souto Lasala, J. A., El conjunto fortificado islámico de Calatayud, Zaragoza, 2005, p. 149 refiere claramente esta cuestión, mientras Torres Balbás, L., «La Torre del Oro, de Sevilla», Obra dispersa I, Al-Andalus, Crónica de la España musulmana,1, Madrid, 1981, p.32 la insinúa. Por ejemplo, se documenta una torre de nueve lados en Molina de Segura y otra, cuyas siete caras se circunscriben en una semicircunferencia, en Socovos. Sobre este último recinto léase Eiroa Rodríguez, J. A., Arqueología e historia de la fortaleza medieval de Socovos, Albacete, 2004. A partir de estos casos puede concluirse que dicha interpretación cobraría una mayor verosimilitud en torres de más de ocho lados. ${ }^{21}$ Tal disposición se refleja gráficamente en Márquez Bueno, S. y Gurriarán Daza, P. Cáceres: una punta de lanza almohade frente a los reinos cristianos, Badajoz, 2006, p. 17.

${ }^{22}$ Se puede consultar la planta del recinto de Écija publicada en VV.AA., Itinerario Cultural de Almorávides y Almohades, Sevilla, 1999, p. 265.

${ }^{23}$ Agradecemos la gentileza de Juan Carlos Castillo Armenteros por habernos facilitado un plano inédito con la ubicación de las albarranas octogonales en el recinto de Andujar.
}

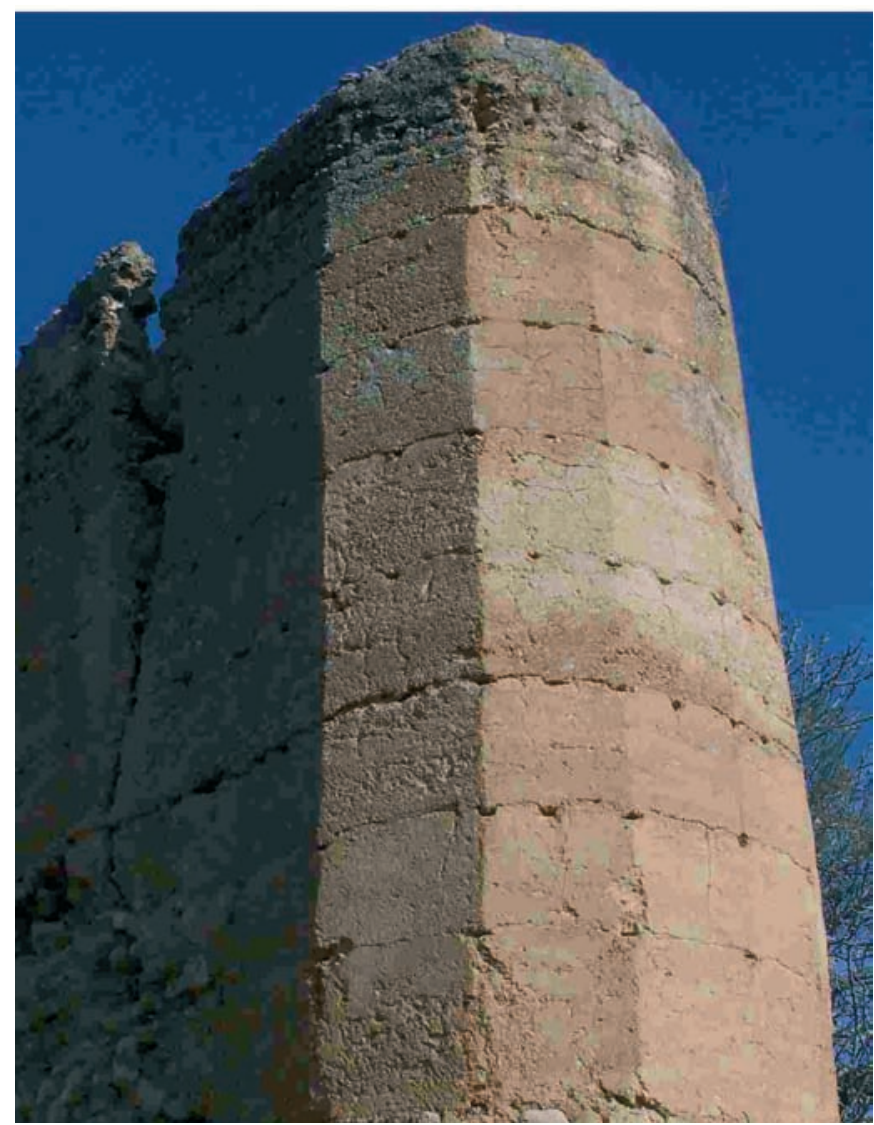

Fig. 7. Torre poligonal del castillo de Socovos (Albacete)

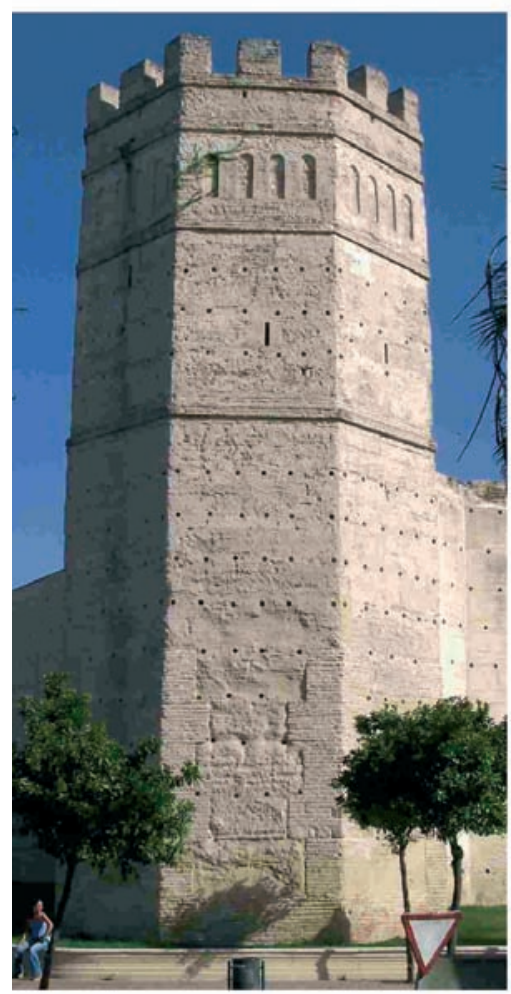

Fig. 8. Torre octogonal del Alcázar de Jerez de la Frontera. 
Fig. 9. Distribución de torres albarranas y poligonales en los territorios almohades peninsulares. No se indican las torres poligonales de Socovos ni de Molina de Segura, por atípicas

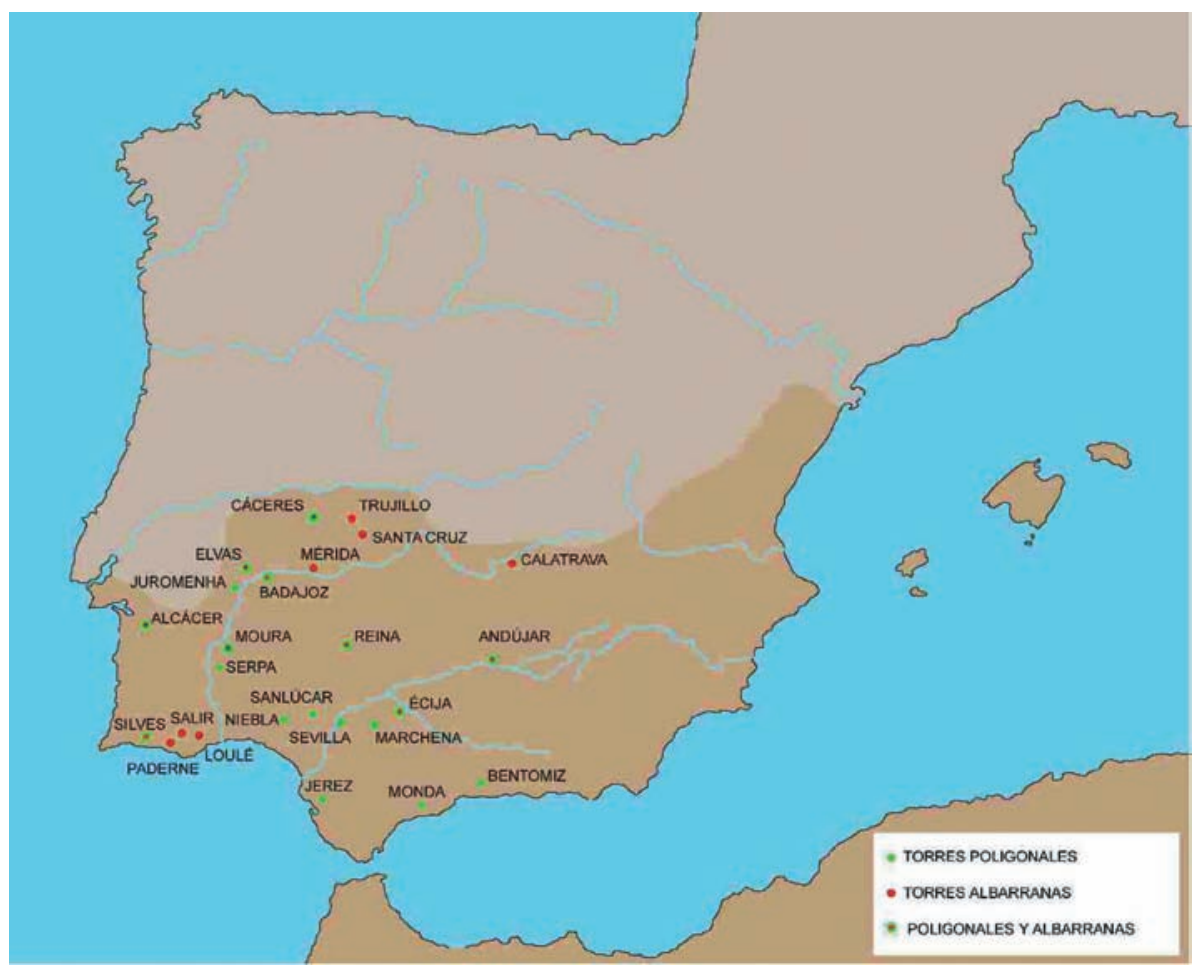

otras flanqueando lienzos rectilíneos. En Elvas, ninguna de las dos poligonales, una adosada y otra albarrana, domina quiebro alguno ${ }^{24}$. En la alcazaba de Reina, la única albarrana octogonal también flanquea un lienzo de trazado recto. Así, la existencia de estos casos pone en entredicho el pretendido valor militar como torre poderosa diseñada exclusivamente para el flanqueo de un ángulo de la fortificación.

En realidad, hasta la aparición de la pirobalística, las habituales torres cuadrangulares y semicirculares cumplían con creces su cometido acorde con las técnicas de asedio y expugnación vigentes; por lo que se podría considerar que tanto las torres albarranas como las poligonales estarían sobredimensionadas en lo que a uso poliorcético se refiere. De hecho, si no hubiese sido así, su construcción se habría hecho extensiva a todo al-Andalus. Sin embargo, es posible comprobar de qué manera proliferan en la mitad occidental del territorio andalusí, mientras que son prácticamente inexistentes en la zona de levante, como vemos gráficamente en los ejemplos representados en la Fig. 9.

Para tratar de explicar este fenómeno, quizá sea necesario reflexionar acerca de las condiciones específicas de cada uno de los diversos solares peninsulares administrados de una forma u otra por los Unitarios, cuyo análisis contribuirá a definir el tipo de dominio o relación que se estable-

${ }^{24}$ Como se observa en el plano publicado en Branco Correia, F., "O sistema defensivo da Elvas islamica", Mil anos de Fortificaçoes na Península Ibérica e no Magreb, Palmela 2002, p. 361. ce entre cada una de tales zonas y el poder central muminí. En una clasificación que atienda a criterios geopolíticos se podrían considerar tres zonas, grosso modo. En primer lugar: Garb al-Andalus, u occidente de al-Andalus, que comprendería los territorios situados entre el Tajo, el límite actual entre Extremadura y La Mancha, Sierra Morena, y curso bajo del Guadiana. En segundo lugar: Centro, ajustable a la actual Andalucía. Y a la postre: Šarq al-Andalus, u oriente de al-Andalus, correspondiente a las actuales comunidades valenciana, murciana y provincia de Albacete.

Por una parte, en el Šarq, tras la sumisión de todo este sector en 1172, los almohades establecen un dominio indirecto, o parcialmente delegado, en el que las antiguas élites ya sometidas son mantenidas en sus $\operatorname{cargos}^{25}$. Tal situación podría estar relacionada con el hecho de que, al fin y al cabo, el levante constituya la periferia del dominio andalusí de los Unitarios, cuyo centro de gravedad es Sevilla. Así mismo, el mantenimiento de una sociedad estructurada y cohesionada, como ésta, liberaría de engorrosas preocupaciones a las autoridades muminíes. Del mismo modo, unas condiciones similares a las del Šarq, en cuanto a cohesión y nivel de articulación, caracterizarían a la sociedad de la zona Centro. Así, el vínculo geográfico de ésta con el centro de poder almohade peninsular, explicaría el tipo de dominio que se establece, directo en este caso.

25 Esta cuestión se refiere en Guichard, P. Al-Andalus frente a la conquista cristiana, Madrid-Valencia, 2001, p. 149 y siguientes. 
En cuanto al Garb, durante todo el período almohade, fue uno de los territorios más desarticulados de todo alAndalus, hecho que puede ser explicado por la confluencia de varios factores relacionados entre sí. Por una parte, desde épocas anteriores ya se arrastraba un manifiesto contraste entre su hábitat disperso y poco denso, y la mayor concentración demográfica del Centro y Šarq. A esto se pueden añadir los catastróficos efectos de la fuerte presión militar ejercida por los reinos cristianos, entre los que destacaría el naciente y agresivo Portugal. De sus actividades y de las reacciones suscitadas en el lado almohade, las mismas crónicas musulmanas dan rendida cuenta.

Por citar algunos ejemplos: en Badajoz, las obras de acondicionamiento y mejora de infraestructuras hidráulicas llevadas a cabo en su alcazaba en 1169 fueron ordenadas y ejecutadas por el poder central ${ }^{26}$. La propia ciudad tuvo que ser abastecida, al menos en tres ocasiones, en 1170,1171 y 1173 , por recuas provenientes de Sevilla, de las que una no llegó a su destino por haber sido interceptada por Geraldo Sempavor ${ }^{27}$. Este mismo caudillo tomó Beja en 1172 y la evacuó unos meses después. Para el retorno de su población, las autoridades almohades se preocuparon de reunir a los supervivientes, a los que se les ofreció una guarnición y obreros para poner a punto las defensas, iniciándose las reparaciones con anterioridad a la llegada de los habitantes. A pesar de los esfuerzos invertidos, la ciudad fue abandonada en 1178, tras unos reveses militares sufridos por los gobernadores de Beja y Serpa, a manos de los portugueses ${ }^{28}$. En fin, para estimular la repoblación de Alcácer do Sal, tras su conquista en 1191, además de guarnecer la plaza con tropas regulares, se subvencionó a la población mediante cantidades mensuales y anuales de fondos cedidos por Ceuta y Sevilla ${ }^{29}$.

Así, todo parece indicar que la sociedad de estos territorios estaba tan desarticulada que no podía mantenerse por si misma, ni siquiera desde Badajoz, incapaz ya de jugar ese papel vertebrador que ostentó en época taifa. En consecuencia, fueron los almohades los que se vieron obligados a asumir tal función mediante el ejercicio de un dominio más directo. Tampoco debemos olvidar que el Garb constituye la frontera más inmediata entre el centro del poder almohade peninsular, Sevilla, y los reinos de León, Portugal y Castilla. Precisamente, mientras éstos dos últimos enfocan su actividad expansiva hacia el Sur musulmán, Aragón tendrá puestas sus miras al norte de los

\footnotetext{
${ }^{26}$ Ibn Șāhị al-Salā, op. cit., 1969, p. 149.

${ }^{27}$ Ibidem, pp. 153, 187, y 233.

${ }^{28}$ Ibn Id̄ārī, op. cit., 1953, pp. 21 y 22.

${ }^{29}$ Ibidem, p. 168 y ss.
}

Pirineos, en Occitánia, hasta la batalla de Muret en 1213. Por este motivo el Šarq no sufrió, durante la segunda mitad del s. XII y principios del s. XIII, la fuerte presión militar padecida por el Garb. Posiblemente, a causa de la conjunción de todas las circunstancias mencionadas, los Unitarios se hicieron cargo del mantenimiento y mejora de, al menos, una porción considerable del conjunto de infraestructuras militares del occidente andalusí. Para ello, emplearon todos los recursos económicos y materiales posibles; incluyendo, según creemos, un cuerpo de alarifes en nómina vinculados al poder central, y al servicio del cual desplegaban un repertorio normalizado de formas, entre las que se incluían torres albarranas y poligonales, con muy probables fines propagandísticos.

En resumen, el vínculo entre las torres poligonales y el poder almohade está tan anudado, que torres de la misma tipología proliferan en los territorios controlados de forma directa por los Unitarios, del mismo modo que son prácticamente inexistentes en aquellas zonas donde ejercen un poder delegado en connivencia con unas élites locales fuertemente implantadas. El prestigio que adquirieron estas obras será tal que, una vez derrocados los almohades, aún perdurarán sus secuelas en poligonales meriníes, por ejemplo en alguna de Algeciras $^{30}$ o en la Chellah de Rabat, y otras cristianas.

\subsection{Accesos monumentales}

A la hora de analizar las puertas monumentales erigidas en diversas fortificaciones andalusíes durante el período almohade, consideramos innecesario insistir en el estudio de la disposición acodada de muchas de aquellas, cuestión suficientemente tratada con anterioridad en numerosos trabajos $^{31}$. Únicamente mencionaremos que su proliferación se producirá en esta época, a pesar de documentarse tal tipología desde periodo omeya ${ }^{32}$. Pero esta práctica poliorcética tendente a dificultar el ingreso, se verá inserta dentro de una reflexión más profunda sobre el propio lenguaje

30 Sería el caso de la albarrana Torre del Espolón del recinto sur meriní de Algeciras, desaparecida hace un siglo escaso. De esta torre véase la interesante acuarela realizada por Ernest L. Lessieux a finales del siglo XIX, y recogida en Jiménez-Camino Álvarez, R. y Tomassetti Guerra, J. M., Carta Arqueológica de Algeciras, Algeciras, 2008, ficha de documentos gráficos N.o 19.

${ }^{31}$ Torres Balbás, L., «Las puertas en recodo en la arquitectura militar hispanomusulmana", Obra dispersa I, Al-Andalus, Crónica de la España musulmana, VII, Madrid, 1981, pp. 122 a 150. Pavón Maldonado, B., Tratado de arquitectura hispano-musulmana II, Madrid, 1999, pp. 403 a 408.

32 Tras las últimas excavaciones y consolidaciones, La Puerta del Barrio de Ágreda, datada como califal, muestra una estructura acodada muy parecida a la que se desarrollará posteriormente en las puertas almohades de la Alcazaba de Badajoz. Vallejo Triano, A., Madinat al-Zahra, guía oficial del conjunto arqueológico, Sevilla, 2004, p. 78 describe una puerta acodada que da acceso por el norte a la zona de los alcázares en Madinat al-Zahra. 
Fig. 10. Fachada interior del acceso monumental de la Qasba de los Udaya, en Rabat, erigido por orden del califa almohade Abu Yusuf Ya'qub Al-Mansur

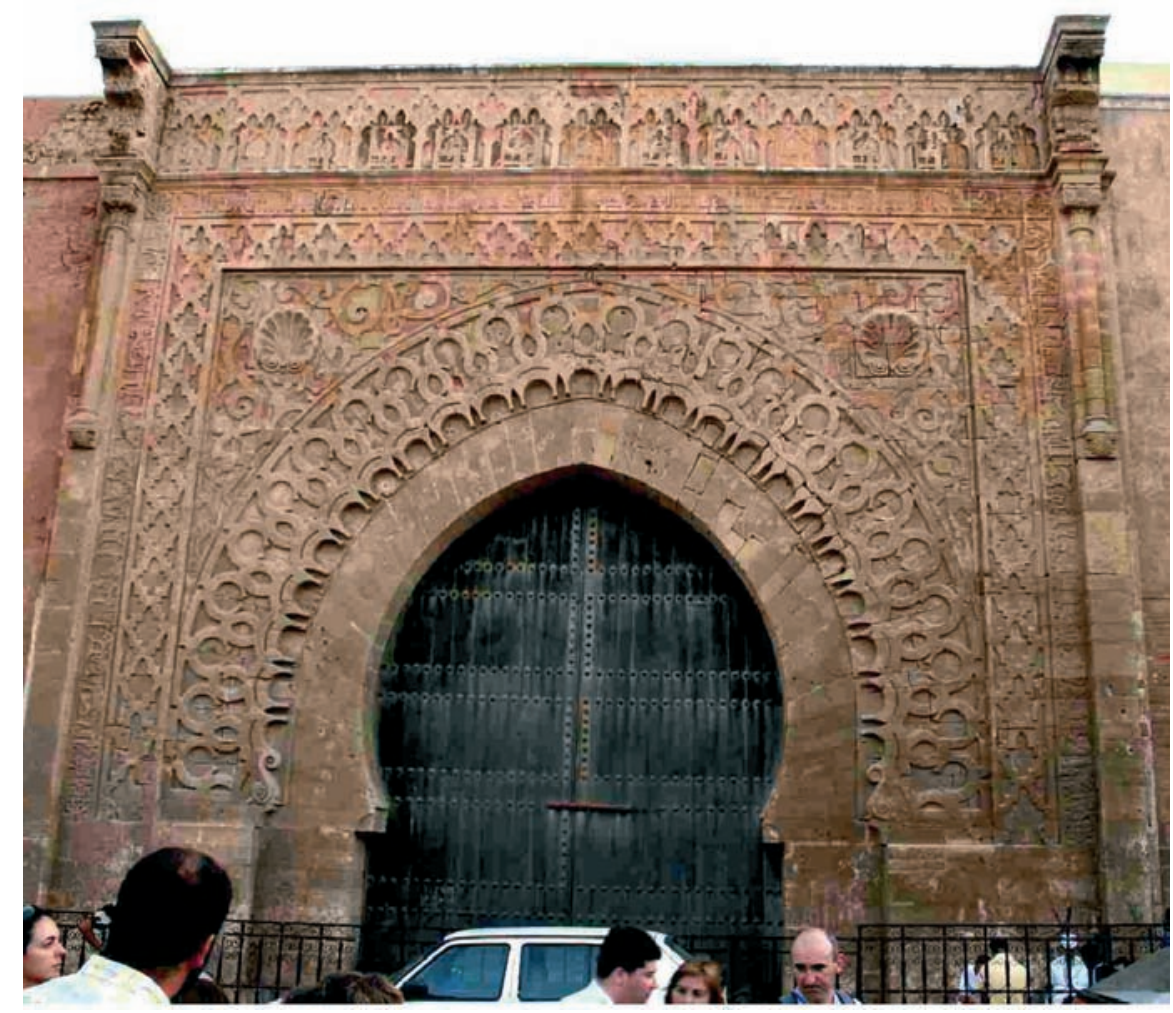

formal de tales accesos, concebidos como uno de los puntos más representativos de una fortificación. Como veremos, los almohades seguirán caminos dispares en la ejecución de estas obras a ambos lados del Estrecho, circunstancia que será el reflejo de las condiciones particulares de cada territorio.

No son pocos los autores que han estudiado las puertas de aparato almohades del Norte de África ${ }^{33}$, refiriendo tanto su ejecución en fina sillería como el esquema compositivo dominado por uno, o varios arcos doblados, de herradura, lobulados, y de medio punto; en torno al que se articulan sus motivos ornamentales: geométricos, vegetales, y epigráficos; y cuyo resultado redundará en el carácter monumental del acceso, poniendo en evidencia sus valores simbólicos con relación al mensaje que los muminíes querían transmitir (Fig. 10).

Sin embargo, el tratamiento formal que reciben estas puertas contrasta claramente con las andalusíes erigidas bajo la misma dinastía, puesto que hasta la fecha no se ha documentado en la península ejemplo alguno similar a los del otro lado del Estrecho, ni siquiera en Sevilla, capital de

\footnotetext{
33 Entre las más recientes aportaciones cabe reseñar a Cressier, P. «Les portes monumentales urbaines almohades: symboles et fonctions", Los almohades: problemas y perspectivas, Volumen I, Madrid, 2006, pp. 149 a 187. Pavón Maldonado, B. "Planimetría de ciudades y fortalezas árabes del norte de África», Cuadernos del archivo municipal de Ceuta, Número 9, Ceuta, 1996, pp. 17 a 162.
}

los almohades en al-Andalus. De hecho, los pocos ejemplos conservados de puertas hispalenses se parecen más a las de cualquier recinto peninsular de provincias que a las de ningún centro de poder almohade en el norte de África (Fig. 11). Por otra parte, es significativo que una fortaleza almohade norteafricana de segundo rango, como Dar alSultan, ostente una versión de las fachadas monumentales de Rabat y Marrakech, pero realizada con técnicas de albañilería ${ }^{34}$. Así, parece que en cada orilla del Estrecho, tanto en capitales como en la periferia, las puertas monumentales seguían sus propios esquemas compositivos. De este modo, habrá que esperar hasta el período nazarí para documentar en al-Andalus puertas monumentales o de aparato, deudoras de las magrebíes ${ }^{35}$ (Fig. 12).

Por el contrario, el modelo cuya presencia se constata de forma sistemática en tierras andalusíes muestra un esquema compositivo muy sencillo regido por un arco ultrasemicircular, a menudo ligeramente apuntado y rehundido respecto del omnipresente alfiz ${ }^{36}$. En cuanto a la decoración, es inexistente en la superficie de la portada

\footnotetext{
${ }^{34}$ Dato que agradecemos a la cortesía de Patrice Cressier.

${ }^{35} \mathrm{El}$ arco de la fachada interior de la Puerta de la Justicia de la Alhambra y la fachada exterior de la Puerta de Armas del mismo recinto, lucen arcos de evidente tradición almohade.

36 Souto Lasala, J. A., Op. Cit., 2005, p. 160 a 162 aporta unas interesantes reflexiones sobre el valor simbólico del arco de herradura.
} 


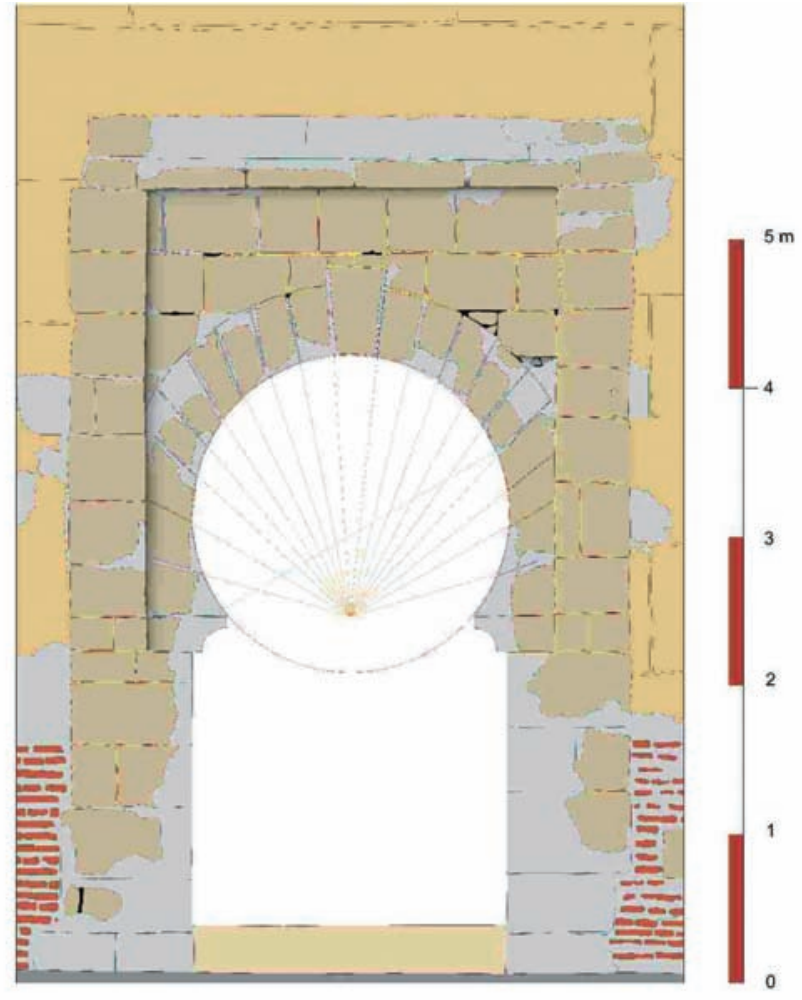

Fig. 11. Alzado fotogramétrico del arco interior de la Puerta de Córdoba en Sevilla. De su trazado geométrico cabe destacar el rectángulo del alfiz generado por un triángulo equilátero

inmediata al vano ${ }^{37}$, ubicándose los escasos elementos ornamentales a modo de fajas situadas en la parte superior, como atestiguan las fortificaciones de Badajoz, Jerez de la Frontera o Niebla.

Tales evidencias nos llevan inevitablemente a preguntarnos por los motivos que condujeron a una misma dinastía a establecer tan radical diferencia entre construcciones que desempeñan una función similar. Cabría la posibilidad de atribuir la apariencia, ciertamente simple y arcaizante de las puertas andalusíes en relación a las magrebíes, a su ejecución por cuadrillas de albañiles ancladas en tradiciones constructivas autóctonas. Pero hemos de tener presente que estos operarios seguían las directrices marcadas por los arquitectos al servicio de los almohades y, precisamente, las puertas siempre constituirán el espacio más susceptible de recibir la mayor concentración de carga simbólica de todo un edificio, de modo que resultaría como mínimo llamativo que se dejase a criterio de los albañiles la configuración de las entradas a sus fortalezas, por lo que manifestamos ciertas reservas sobre esa opción. Así, a falta de una explicación satisfacto-

\footnotetext{
${ }^{37}$ En la fachada primitiva de la puerta de Sevilla, en el recinto iliplense, subsisten porciones de la jabelga, presumiblemente original, sobre la que no parece haberse trazado motivo ornamental alguno.
}

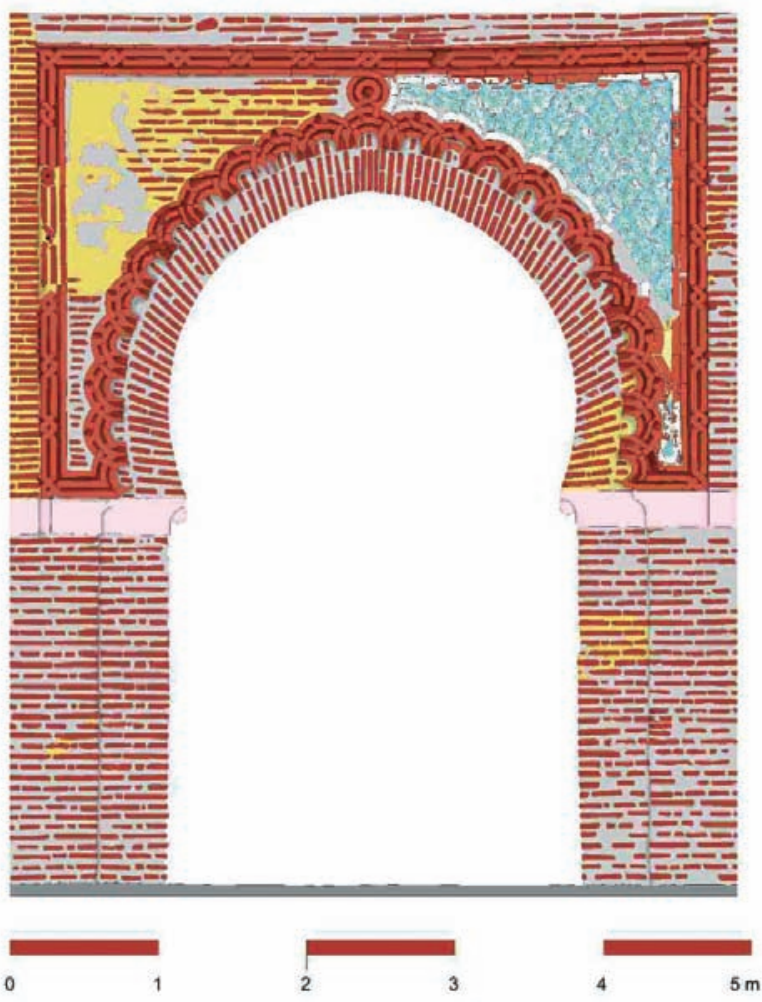

Fig. 12. Alzado fotogramétrico del arco interior de la Puerta de la Justicia, erigida en 1348 en la Alhambra de Granada. Se aleja de la tradición omeya aproximándose a la almohade africana

ria, nos atrevemos a sugerir que la estética tradicional de estos elementos debió obedecer a una clara intención, que no es otra que la de establecer un vínculo entre las dinastías almohade y omeya a través de sus obras monumentales, como sucede, por ejemplo, con las puertas.

La dinastía omeya todavía era recordada en al-Andalus, siglo y medio después de su desaparición, como la depositaria del auténtico Califato y, por lo tanto, cargada de una importante dosis de legitimidad y poder. Además, suponía el momento de mayor esplendor andalusí, lejos de la nueva situación de presión que existía con los reinos cristianos. Los Unitarios, mediante la ostentación de una estética de accesos monumentales cercana a la desarrollada en época omeya, debieron pretender presentarse como los sucesores naturales y legítimos de los califas cordobeses y canalizar, en beneficio propio, su recordado prestigio. Conviene no olvidar la perentoria y crónica necesidad que tuvieron los almohades de justificar su autoridad ante los andalusíes. Incluso, los ejemplos de portadas almohades andalusíes más elaboradas siguen remitiendo a prototipos omeyas, como es el caso de las puertas monumentales del recinto de Niebla, en las que el esquema compositivo que las rige deriva directamente del observado en los mihrabs y fachadas de las mezquitas omeyas (Fig. 13). 


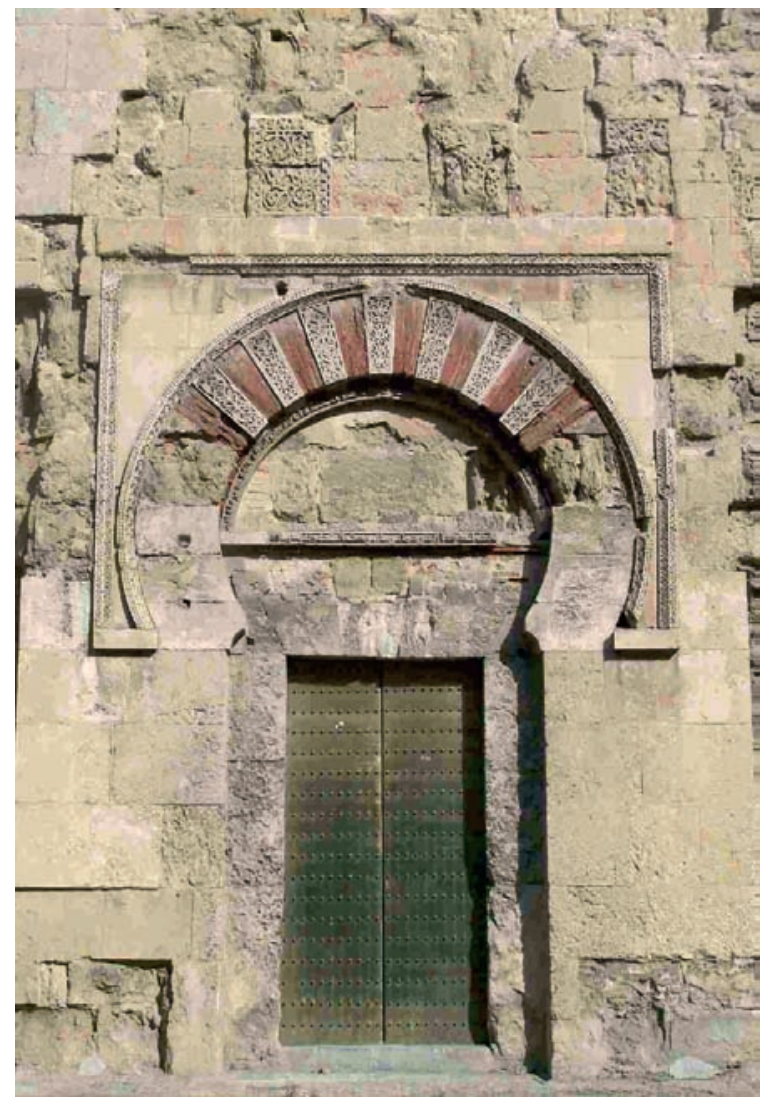

Fig. 13. Puerta de San Esteban de la mezquita de Córdoba, en la que se muestra el esquema compositivo regido por un arco monumental de herradura coronado por un friso de arquillos ciegos. Obsérvese la similitud de composición con las puertas de las figuras 15 y 16

No sólo se constatan vínculos formales entre los accesos monumentales, sino también en cuanto a materiales empleados, de modo que los almohades, a imitación de los omeyas, erigirán sus puertas con piezas pétreas labradas ex novo. Tal acción constituye, a nuestros ojos, otro indicador del especial interés de los muminíes en dotar a tales portadas de una especial carga simbólica y propagandística. No hay que olvidar que los sillares empleados en otras partes de los recintos almohades de tâbiya, en bases de lienzos y torres, en muchos casos eran de acarreo ${ }^{38}$.

A la hora de estudiar los accesos monumentales conservados en la península Ibérica, cabe referir que es realmente escaso el número de ejemplos subsistentes de los que tengamos más o menos clara la cronología. Por sus características formales y edilicias podemos asignar a este período ciertos accesos de los recintos de Mértola, Elvas, Badajoz, Aroche, Niebla, Sevilla, Carmona, Marchena, Jerez de la Frontera, Medina Sidonia y Denia. No obstante, mencionaremos dos puertas a las que cabría la posibilidad

${ }^{38}$ Hecho que se comprueba en las cercas de Cáceres, Juromenha, Niebla, Carmona, Écija y Reina, o en la Alcazaba de Badajoz.

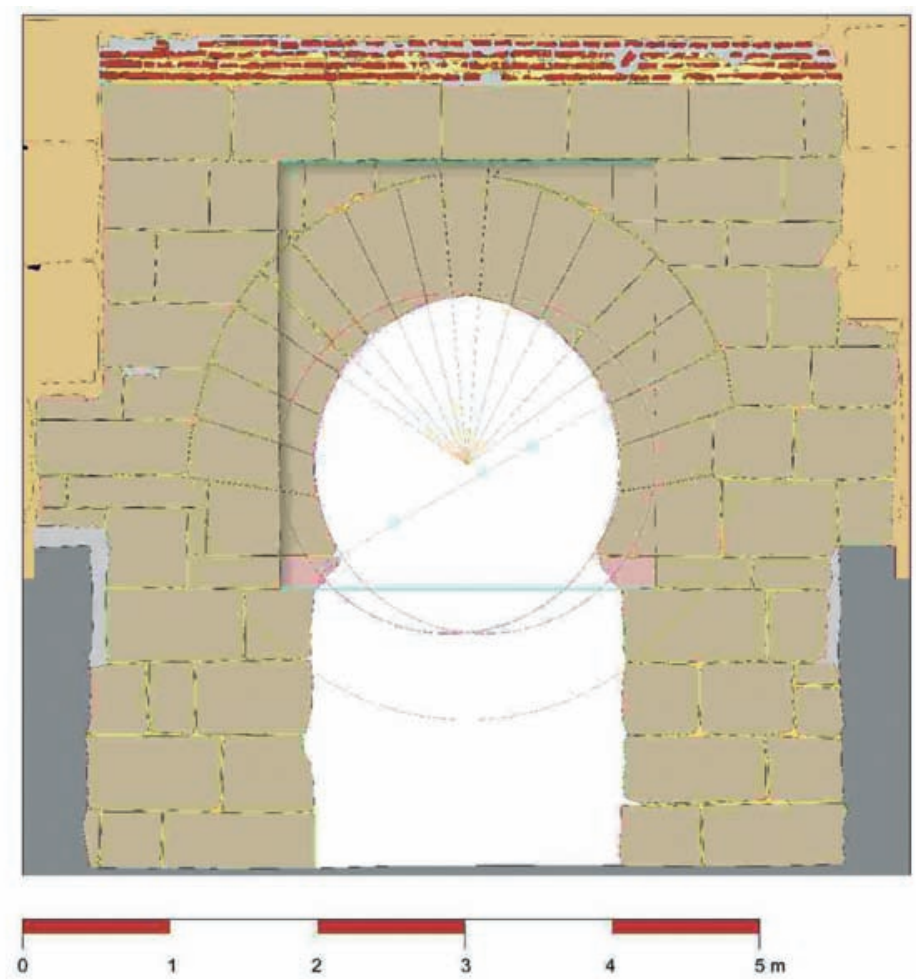

Fig. 14. Alzado fotogramétrico de la fachada interior de la Puerta del Buey de Niebla. Obsérvese que el trazado geométrico del alfiz es idéntico al de la Puerta de Córdoba en Sevilla, representada en la figura 11

de fijar semejante datación, dadas sus características materiales, formales y geométricas: el Arco de las Pesas en Granada y la puerta de la alcazaba de Loja ${ }^{39}$, a las que podríamos añadir tal vez la Puerta de Belén en Córdoba. Especial atención merecen los recintos de Badajoz y Niebla, por ser los únicos en los que se ha conservado una serie más o menos extensa de arcos monumentales distribuidos en varias puertas, frente a uno o dos arcos por única puerta subsistente en cada uno de los restantes recintos referidos.

En Niebla, de las cinco puertas almohades del recinto urbano, Sevilla, Socorro, Buey, Agua y Embarcadero, todas conservan fachadas monumentales escasamente alteradas excepto la última referida. Se trata de torres-puerta con entrada monumental exterior en un lateral de la torre, cuyo interior se cubre con bóveda baída, y salida al interior de la ciudad a través de otro arco monumental tras efectuar un simple codo (Fig. 14). Únicamente la Puerta del Socorro

\footnotetext{
39 Martínez Núnez, M. A., «Epigrafía y propaganda almohades», Al-Qantara XVIII, Madrid, 1997, p. 427 mediante el análisis de la banda epigráfica que preside la puerta de la Alcazaba de Loja, data su construcción a finales del período almohade.
} 

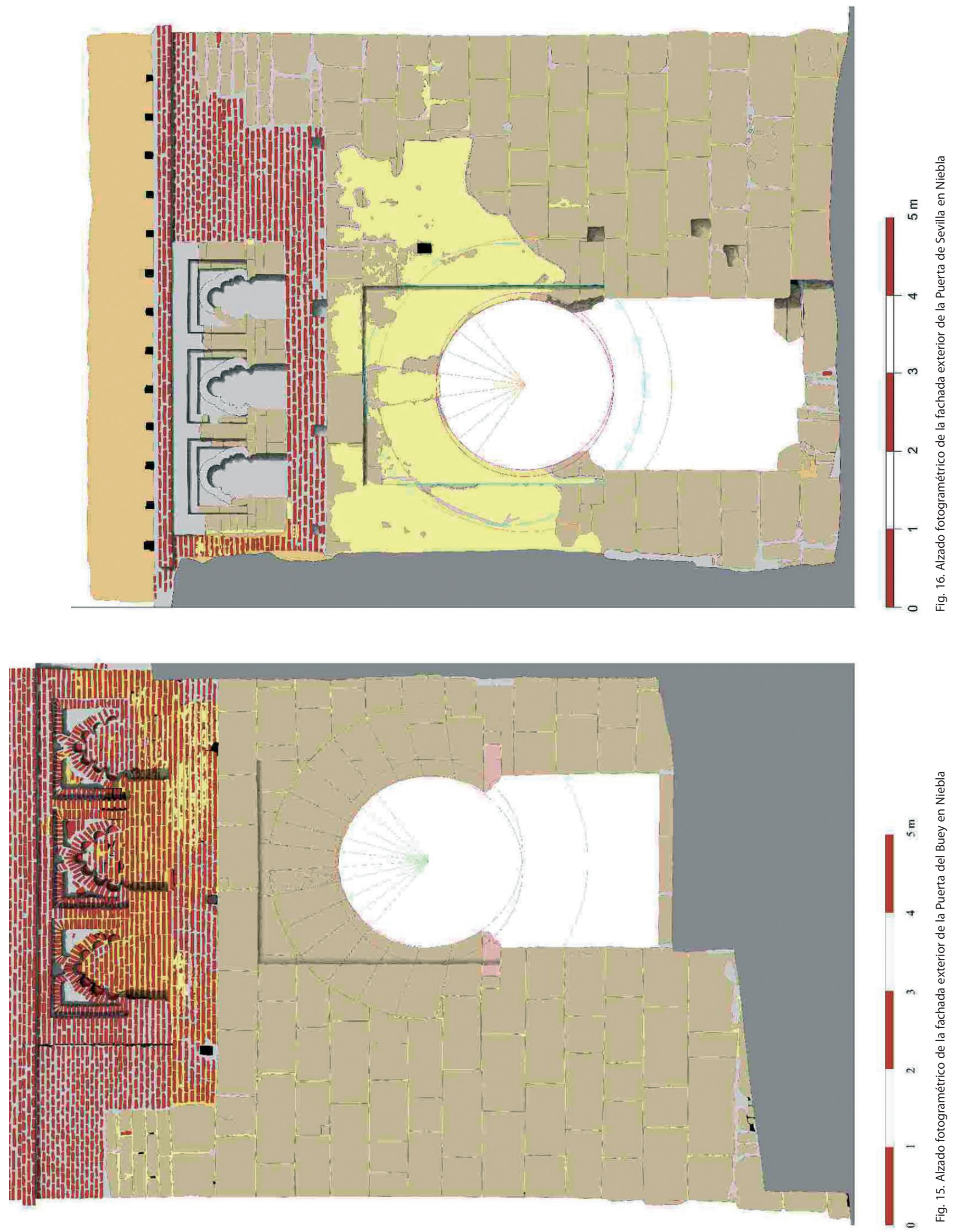
presenta una variación de este esquema en la cubierta del espacio interior de la torre-puerta por una bóveda de cañón y la inexistencia de portada mirando a la ciudad. Todos los arcos de las portadas siguen el mismo esquema tanto en ejecución material, configuración formal como trazado geométrico. En lo que a ejecución material se refiere, se trata de obras de cantería con sillares labrados $e x$ novo y aparejados al milímetro, reservándose el ladrillo, eventualmente combinado con sillares, para la zona superior de la fachada. Solamente en las impostas de los arcos exterior e interior de la Puerta del Buey se emplean piezas marmóreas. En cuanto a la configuración formal, se repite el consabido esquema de arco de herradura ligeramente apuntado y rehundido respecto del alfiz, sobre el que se emplaza en las caras exteriores de las puertas de Sevilla y del Buey un friso de tres arquillos ciegos polilobulados (Figs. 15 y 16). Y por último, en el trazado geométrico, aunque es cierto que hay ligeras diferencias en la concepción de los alfices, se observa una gran uniformidad en el trazado de los arcos mediante un par de circunferencias levemente desplazadas y casi siempre tangentes al alfiz. En todos los casos, el despiece de las dovelas centrales se dirige al centro geométrico del mentado par de circunferencias y la línea de la rosca corta el alfiz. En resumidas cuentas, el grado de homogeneidad, a todos los niveles, atestiguado por las puertas del recinto de Niebla permite aventurar la mano de una única cuadrilla, o varias dirigidas por un jefe de obra con unos criterios uniformes y estrictos.

En la Alcazaba de Badajoz han llegado a nuestros días tres accesos que poseen arcos monumentales erigidos bajo los almohades: el Postigo de la Coracha, la Puerta del Capitel y la Puerta del Alpéndiz.

El Postigo de la Coracha se trata de un acceso directo flanqueado por una torre adosada a diestra de su fachada exterior. Su composición formal se rige por un arco ciego enjarjado, de herradura un tanto aguda, impostas en nacela y ligeramente rehundido respecto al alfiz que lo enmarca. A su vez, dicho arco cobija un pequeño postigo rematado por un arco escarzano.

En cuanto a los materiales, tanto el espacio comprendido entre el vano de acceso y el arco ciego ultrasemicircular, como las albanegas de este último, se resuelven mediante sillares de labra poco cuidada, combinándose con ladrillos en la rosca del arco de herradura y en la zona periférica de la portada. Precisamente, lo tosco del corte de sus dovelas justifica el uso de ladrillo y abundante mortero para encajar las piezas. De este modo, la irregularidad del aparejo pretende disimularse mediante líneas incisas en el mortero, tratando de aparentar un acabado más regular. Por el con- trario, el empleo de dovelas mejor trabajadas en el arco escarzano permite el uso exclusivo de piezas pétreas. Es posible que incluso llegasen a emplearse algunas piezas de acarreo, como parecen confirmar las desiguales impostas marmóreas. Lo que sí parece evidente es el uso de piezas pétreas carentes de función tectónica dada su notable delgadez, aparejándose pues a modo de chapado de carácter ornamental, orientado al juego de planos en diferentes profundidades, definidos por la rasante exterior de la fachada, el plano de las albanegas y la superficie del arco escarzano.

El esquema geométrico que rige la puerta podría considerarse generado a partir de un gran triángulo equilátero, cuya base y altura son las del rectángulo que define el alfiz desde la línea superior de las impostas. Las dimensiones totales de la puerta vienen dadas por la suma de este rectángulo y otro idéntico al anterior, pero situado inmediatamente por debajo. El arco de herradura se determina, por una parte, mediante otro triángulo equilátero, menor que el primero, pero con el que comparte base, y por otra, por dos circunferencias levemente desplazadas tangentes al alfiz. El despiece del arco va dirigido al centro de la línea de las impostas, que es la común entre los rectángulos referidos. Por último, la intersección entre el rectángulo del alfiz y la circunferencia que inscribe al triángulo que lo define coincide con el enjarje del arco de forma muy aproximada (Fig. 17).

Las puertas del Capitel y del Alpéndiz responden al mismo esquema en planta y alzado, pues ambas se disponen a modo de bastión rectangular saliente en el que se abre un primer arco monumental en uno de los lados perpendiculares a la muralla, de manera que queda flanqueado a izquierda por la propia muralla y a diestra por una torre. Tras acceder a un patio rectangular, a cielo abierto, se gira a la izquierda para penetrar en el interior de la Alcazaba a través de un segundo arco de carácter menos monumental que el anterior.

Las fachadas principales de estas dos puertas son idénticas en cuanto a ejecución material, forma y trazado geométrico. Así, ambas se erigen mediante sillares de granito de nueva labra aparejados al milímetro, con impostas marmóreas. Formalmente, ostentan un vano con arco enjarjado de herradura ligeramente aguda y levemente rehundido respecto al alfiz que lo enmarca. Las impostas son anaceladas. El esquema geométrico que rige las fachadas se define por dos pares de circunferencias levemente desplazadas, que dan la altura de los vanos y la forma ligeramente aguda de los arcos, y son tangentes al alfiz. En la Puerta del Capitel las líneas de despiece del arco convergen en el centro de la línea superior de las impostas, 


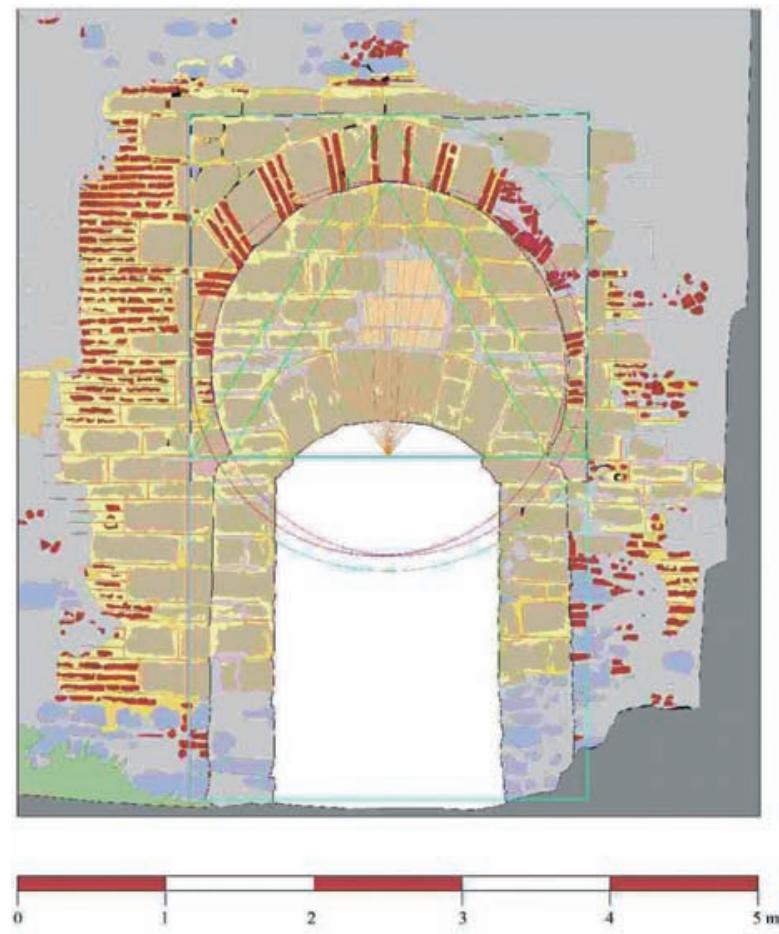

Fig. 17. Alzado fotogramétrico del arco exterior de la Puerta de la Coracha (Badajoz). Los morteros originales no erosionados se representan en amarillo claro con las líneas incisas en naranja. Los morteros originales desgastados aparecen en amarillo oscuro y los morteros modernos en gris

mientras que el alfiz queda definido por un cuadrado cuya base coincide con la línea inferior de las impostas. Justo a la inversa que en la del Alpéndiz, en la que las dovelas se dirigen al centro de la línea inferior de las impostas y el cuadrado que define el alfiz se apoya en la línea superior de las impostas, tratándose al fin y al cabo de ligeras variaciones sobre el mismo trazado geométrico (Figs. 18 y 19).

De las fachadas secundarias de estas puertas sólo se conserva la del Capitel. A pesar de que formalmente sigue el mismo esquema que las principales, su ejecución material se asemeja a la del Postigo de la Coracha. En cuanto al esquema geométrico, es idéntico al que rige el primer arco del Capitel excepto en el cuadrilátero que delimita el alfiz, que en el ejemplo que nos ocupa, parece que viene definido por un triángulo equilátero, pero con mucha menos precisión que en el Postigo de la Coracha (Fig. 20).

En resumen, el valor simbólico y propagandístico de las puertas de la alcazaba pacense vendría refrendado además por la propia monumentalidad de las fachadas, conseguida como ya hemos visto mediante una cuidada ejecución, el uso de materiales nobles y el empleo de relaciones métricas concisas. Precisamente, en una época en la que predomina, de forma abrumadora, el uso de técnicas de al-

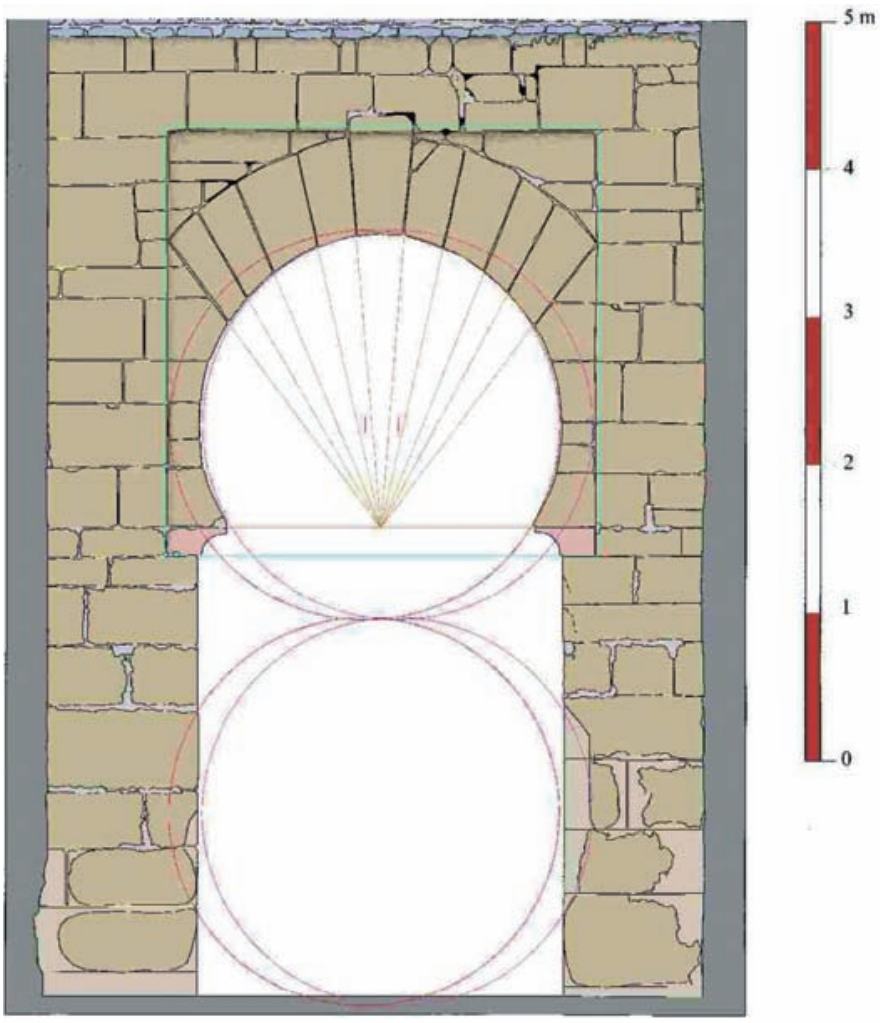

Fig. 18. Alzado fotogramétrico de la hipotética apariencia original del exterior del primer arco de la Puerta del Capitel en la Alcazaba de Badajoz, con su trazado geométrico

bañilería frente a las de cantería, el empleo de sillares labrados ex professo en la arquitectura almohade se limitará a construcciones puntuales, que dado su carácter excepcional denotan el especial cuidado puesto en ellas. Esta es la razón por la que las llamadas técnicas de albañilería, que englobarían el uso de encofrados, mampuestos y ladrillos, se emplearan en puntos de importancia secundaria como el Postigo de la Coracha, el segundo arco del Capitel y seguramente la segunda puerta del Alpéndiz. En lo referente a los esquemas geométricos que rigen todas estas puertas, principales y secundarias, parece que el grado de monumentalidad de las mismas está directamente relacionado con el conjunto de recursos geométricos elegidos para cada vano. Así, mientras que el alfiz de las más monumentales se define mediante un cuadrado, más o menos preciso, el alfiz de las de segundo rango se forma por un rectángulo que lleva inscrito un triángulo equilátero.

En cualquier caso, aunque hubiesen trabajado diferentes cuadrillas, unas de "canteros» y otras de «albañiles», en la erección de estos accesos monumentales, existe, como en el caso de Niebla, una unidad de criterios que da uniformidad al conjunto de las puertas de la alcazaba y de los que seguramente sería responsable una misma persona. 


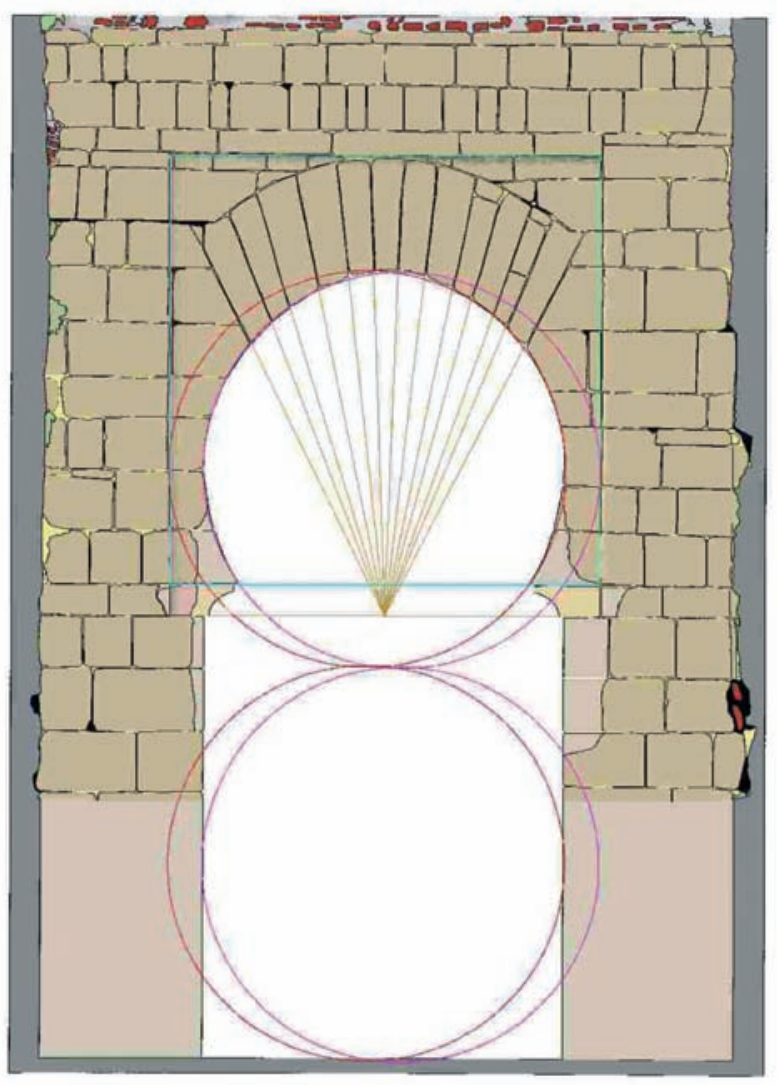

Fig. 19. Alzado fotogramétrico de la hipotética apariencia original del exterior del primer arco de la Puerta del Alpéndiz en la Alcazaba de Badajoz, con su trazado geométrico. En color gris se reconstruye la parte desaparecida y enterrada de la fachada, y en naranja pálido las impostas

Antes de concluir este apartado, no se debe pasar por alto una cuestión que se revela evidente, que es el mayor coste de estas puertas de aparato en relación a lo que suponía la erección de lienzos y torres, no sólo por la diferencia de materiales y procedimientos de la puesta en obra, sino también a causa de la mayor especialización y pericia necesarias en la erección de aquellas. Además, el número de cuadrillas de canteros debía ser muy escaso respecto a la abundancia de tapiadores dedicados a levantar muros y bastiones.

El ejemplo portugués de Paderne puede resultar muy ilustrativo de este asunto. Se trata de un pequeño hișn, aproximadamente rectangular, cuya superficie no supera la tercera parte de una hectárea, lo que no impide que esté dotado de los característicos atributos de la poliorcética almohade, puesto que además de ostentar encintados en sus estructuras hormigonadas, la única torre que posee es una contundente albarrana que flanquea el frente más accesible. Incluso conserva la puerta de acceso en codo simple, sólo que en este caso no se trata del canónico arco de herradura labrado en fina cantería, sino de un arco de medio punto aparejado con simples mampuestos. Esta

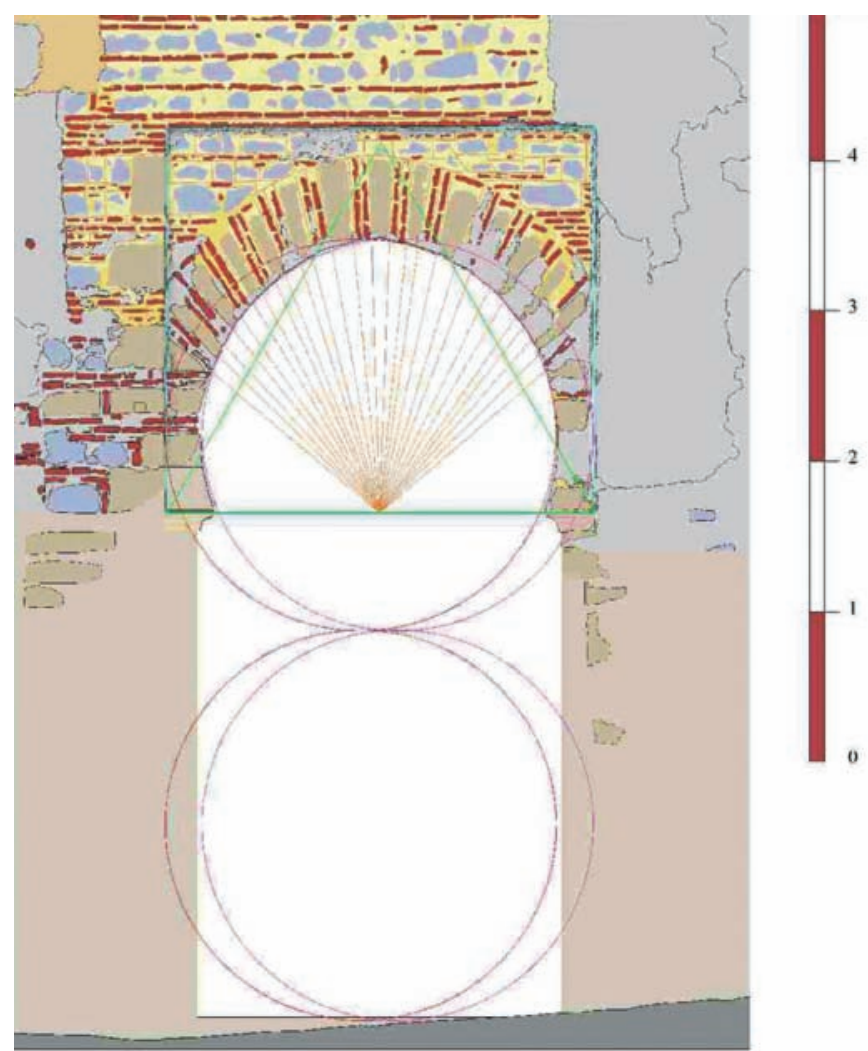

Fig. 20. Alzado fotogramétrico de la hipotética apariencia original del exterior del segundo arco de la Puerta del Capitel, con su trazado geométrico

inexpresiva puerta, nada acorde con las tan arquetípicas tapias encintadas y albarrana, ha llevado a la confusión a algún autor que ha considerado una refacción del arco en época cristiana que hubiera desfigurado una apariencia original más acorde con lo esperado ${ }^{40}$. No obstante, tras una minuciosa observación de los paramentos, se comprueba que tanto el arco que une la albarrana con su lienzo contiguo, como el que configura el acceso al recinto, forman una única unidad constructiva con la obra encofrada, por lo que se les puede atribuir sin ningún género de dudas una cronología almohade (Fig. 21).

Es posible que la decisión de no dotar a este recinto de una portada emblemática se debiera a una conjunción de circunstancias entre las que se podría considerar una coyuntural escasez de recursos económicos, o que la escasa entidad demográfica y administrativa del núcleo estuviera asociada a una inversión económica acorde con sus características, que hubiera conducido a la erección del acceso mediante técnicas de albañilería. En cualquier caso, una

40 En este sentido se pronuncia Pavón Maldonado, B., Ciudades y fortalezas lusomusulmanas, Madrid, 1993, p. 82. 


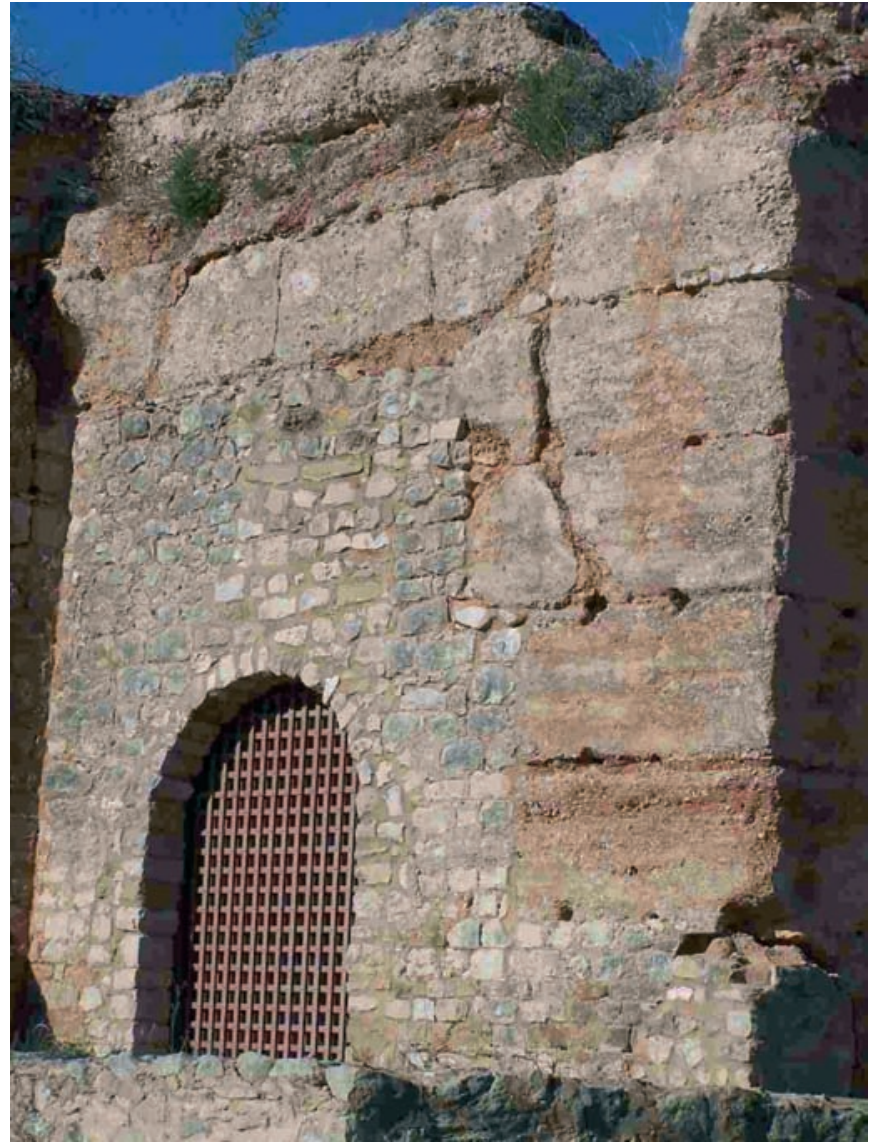

Fig. 21. Puerta del castillo de Paderne (Portugal)

respuesta satisfactoria pasaría por indagar qué vínculos existieron, y de qué naturaleza, entre esta población y el poder almohade.

\section{EQUIPOS DE ARQUITECTOS Y OPERARIOS EN TRÁNSITO}

En los apartados anteriores ya hemos adelantado la existencia de un cuerpo de arquitectos o alarifes «en nómina», al servicio de la autoridad, que diseñaban la imagen arquitectónica que los muminíes querían mostrar de su mensaje político y religioso. Tal perfil estaría integrado por elementos como las puertas monumentales, torres albarranas, torres poligonales, e incluso por el empleo de un acabado superficial común en todas las obras militares, cuya ejecución material recaía en un conjunto de cuadrillas u obreros especializados.

Ante la evidente diferenciación entre obras de albañilería y cantería, vistas en el caso de la Alcazaba de Badajoz, cabe preguntarse acerca de la identificación de dichos tipos de obra con sus correspondientes operarios especializados. Dicho de otro modo, ¿se puede hablar de albañiles y canteros, o bien de obreros que desempeñan las funciones de ambos? Desde luego, las crónicas existentes sobre periodo almohade dan pistas ambiguas, pues suelen referir a los operarios bajo el nombre genérico de «obreros» o «albañiles» en el sentido más amplio, o citan algunos oficios especializados tales como carpinteros, aserradores y yesistas $^{41}$. De cualquier manera, la precisión y perfección de la ejecución de las obras de cantería de las portadas monumentales de las fortalezas reflejan una seguridad y un dominio técnico vinculable a un elevado nivel de especialización dentro de las técnicas constructivas.

Lo que sí refieren claramente las crónicas es la movilidad de esos alarifes y operarios no sólo dentro de alAndalus, sino también entre la Península y el norte de África, como ya se ha referido. Tal tránsito también es consecuencia del estado en el que se encuentra sumido el Garb al-Andalus, en el que la inestabilidad, debida sobre todo a la presión cristiana, obliga a los almohades a prestar continuas y especiales atenciones a tan sensible territorio. De hecho, al margen de las operaciones militares para detener y contrarrestar los incesantes ataques lusos, las fuentes recogen todas las acciones estatales orientadas a la consolidación de la presencia musulmana en el territorio mediante reconquistas, repoblaciones y reconstrucciones por albañiles traídos desde diferentes puntos del Garb ${ }^{42}$. Así, en los aspectos que nos conciernen, el análisis, tanto de las crónicas como de los vestigios arquitectónicos diseminados por todo el occidente andalusí, parece indicar que los Unitarios se hicieron cargo, de forma directa, de su refortificación y guarnición, por lo que, además de tropas, debieron desplazar de forma habitual cuadrillas de obreros y algún que otro alarife según las necesidades.

Creemos que es posible detectar con claridad alguno de esos movimientos entre localidades tan distantes como Badajoz y Carmona, en lo que se refiere a canteros o alarife que los dirigiera, puesto que, tras un análisis meticuloso efectuado sobre el segundo arco de la Puerta de Sevilla en Carmona, se ponen en evidencia las enormes similitudes con las monumentales de Badajoz en cuanto a materiales empleados y su disposición, forma, composición y metrología ${ }^{43}$. De hecho, el trazado geométrico del referido arco la Puerta de Sevilla aúna las pequeñas variaciones del mismo esquema

\footnotetext{
${ }^{41}$ Referencias específicas a las funciones de los que intervienen en las obras aparecen en Ibn Iari, op. cit., 1953, pp. 20 y 97, e Ibn Șāhib al-Salā, op. cit., 1969, pp. 22, 50, 149, 195 a 198.

${ }^{42}$ Ibn Id̄ārī, op. cit., 1953, p. 20.

${ }^{43}$ El primero en reparar en la similitud entre estas puertas fue Pavón Maldonado, B., op. cit., 1999, p. 438. Por otra parte, Jiménez Martín, A., La Puerta de Sevilla en Carmona, Sevilla, 1989, p. 197 atribuye al arco de Carmona, nombrado como B2, una cronología de principios del s. $\mathrm{x}$ basada en un análisis metrológico y formal incorrecto.
} 


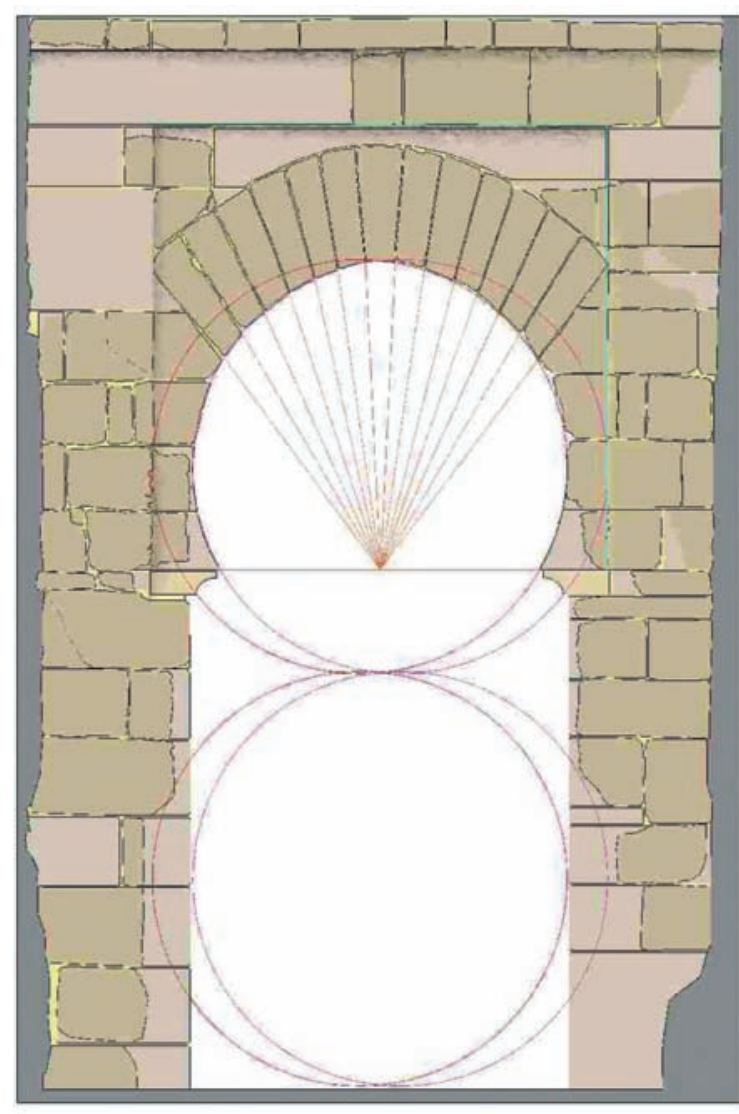

Fig. 22. Alzado fotogramétrico de la hipotética apariencia original del arco almohade de la Puerta de Sevilla en Carmona, con su trazado geométrico. En color gris se reconstruye la parte desaparecida o dañada de la fachada, y en naranja pálido las impostas

que rige las fachadas principales del Alpéndiz y Capitel, de modo que se hace coincidir en una sola línea el origen del despiece del arco y la base del cuadrado que define el alfiz (Fig. 22). Tales semejanzas no se constatan hasta esos extremos en las demás puertas monumentales andalusíes identificadas como almohades (Figs. 23-25). Únicamente el Arco de las Pesas de Granada ostenta un trazado idéntico al arco principal de la Puerta del Capitel. A pesar de que tradicionalmente se le ha venido adjudicando a aquél una cronología zirí (siglo XI), en recientes investigaciones de los arqueólogos Ana Palanco Noguerol y José María Martín Civantos se retrasa la erección de tal acceso al siglo $\mathrm{XI}^{44}$, por lo que, al menos, se abre la posibilidad de encuadrar sincrónicamente o en momentos cercanos los arcos de las Pesas y Capitel. No obstante, evidentes diferencias en su ejecu-

${ }^{44}$ Este dato inédito se debe a la cortesía del arqueólogo José María Martín Civantos.

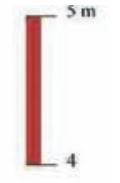

ción material nos inclinan a descartar que esta puerta granadina tenga su origen en el mismo impulso constructor que las pacenses (Fig. 26).

Otro detalle que, en nuestra opinión, podría relacionarse con el desplazamiento de cuadrillas es la aparición en Badajoz de detalles formales como las fajas o impostas que suelen ubicarse, con mayor protagonismo, en torres, y de manera más discreta en algunos lienzos, sobre todo en portadas, y que normalmente marcan el inicio de la cámara de una torre, del pretil y de la línea de merlatura. La difusión de este peculiar complemento ocupa un lugar muy concreto y de concisos límites geográficos dentro de la edilicia almohade en la Península, por lo que su localización se restringe a unos cuantos núcleos del medio y bajo Guadalquivir. con la única v aleiada excebción de Badaioz.

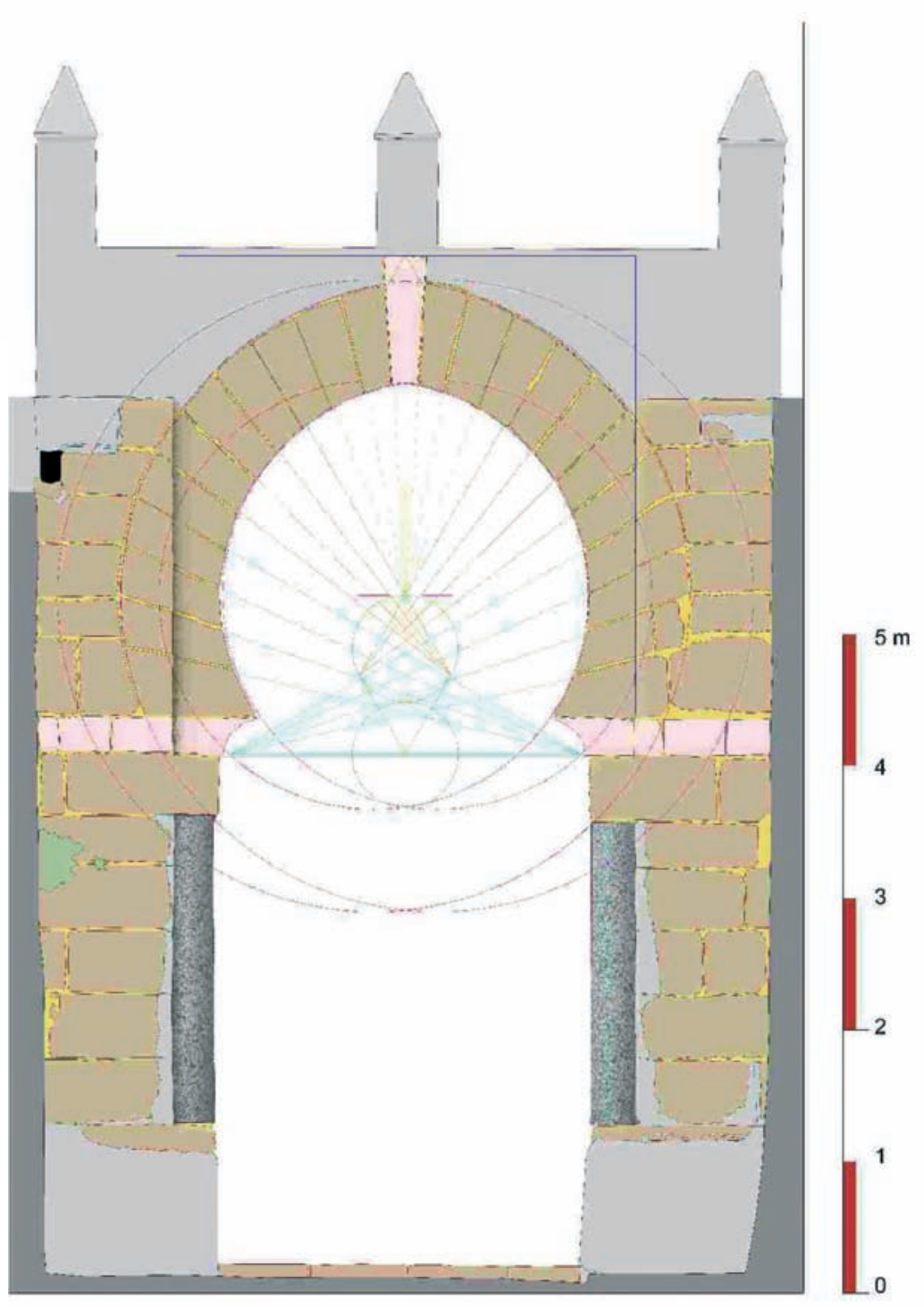

Fig. 23. Alzado fotogramétrico del Arco exterior de la Pastora en Medina Sidonia. Ostenta, con diferencia, el trazado geométrico más complejo de todas las puertas de aparato almohades peninsulares 


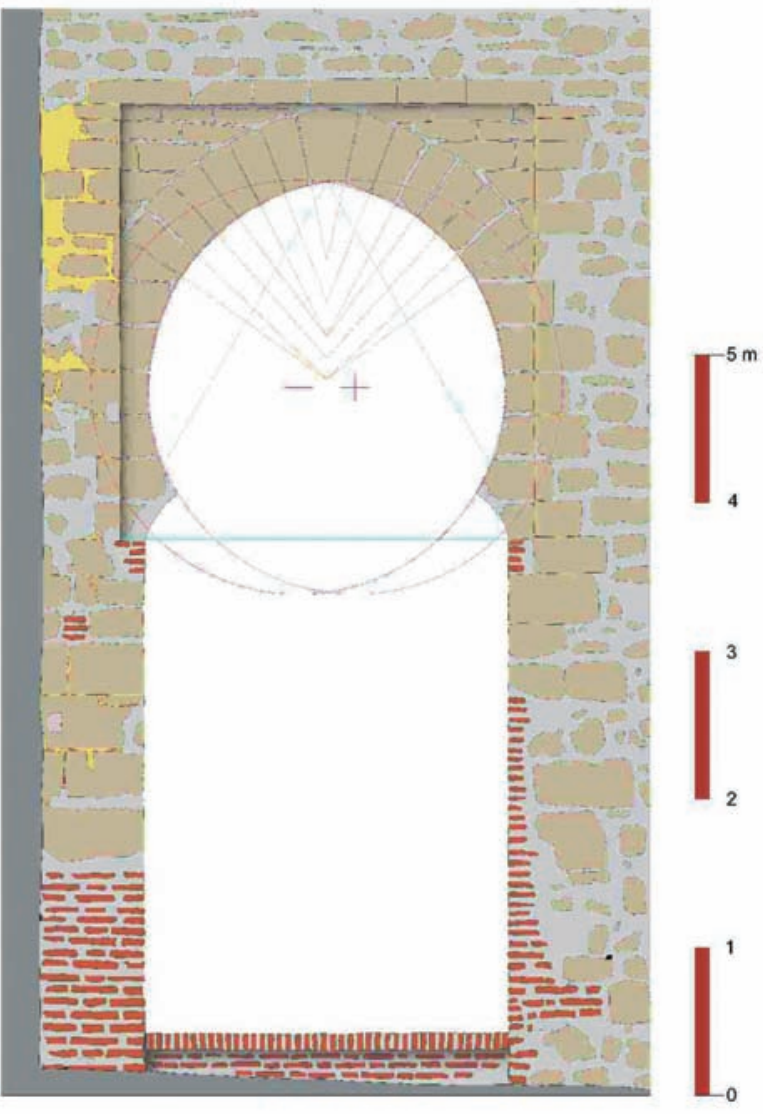

Fig. 24. Alzado fotogramétrico de la Puerta de Morón en Marchena, con su trazado geométrico. Su concepción espacial como torre-puerta acodada y sin bóveda la aproxima a la referida Puerta de Córdoba en Sevilla

En cualquier caso, estos grupos de arquitectos y operarios no se limitaron a trabajar en la capital del Guadiana, sino también se debieron desplazar a la cercana Elvas para ejecutar labores de la misma índole. En esta población, la Porta do Templo ostenta una fachada y organización en planta idéntica a las puertas del Alpéndiz y Capitel que no

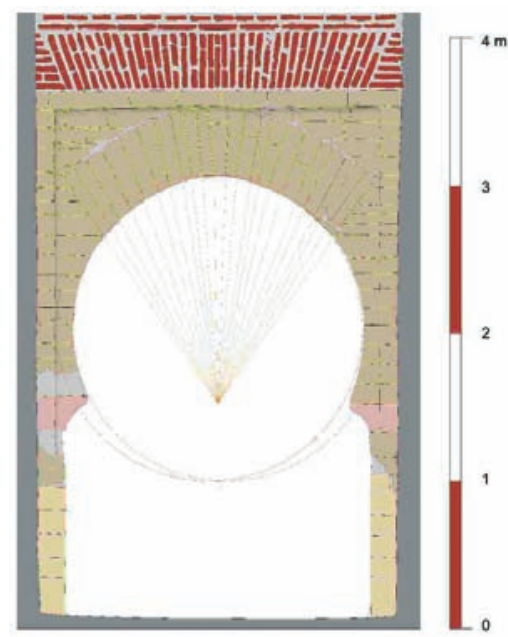

Fig. 26. Alzado fotogramétrico del Arco de las Pesas en Granada, con su trazado geométrico.

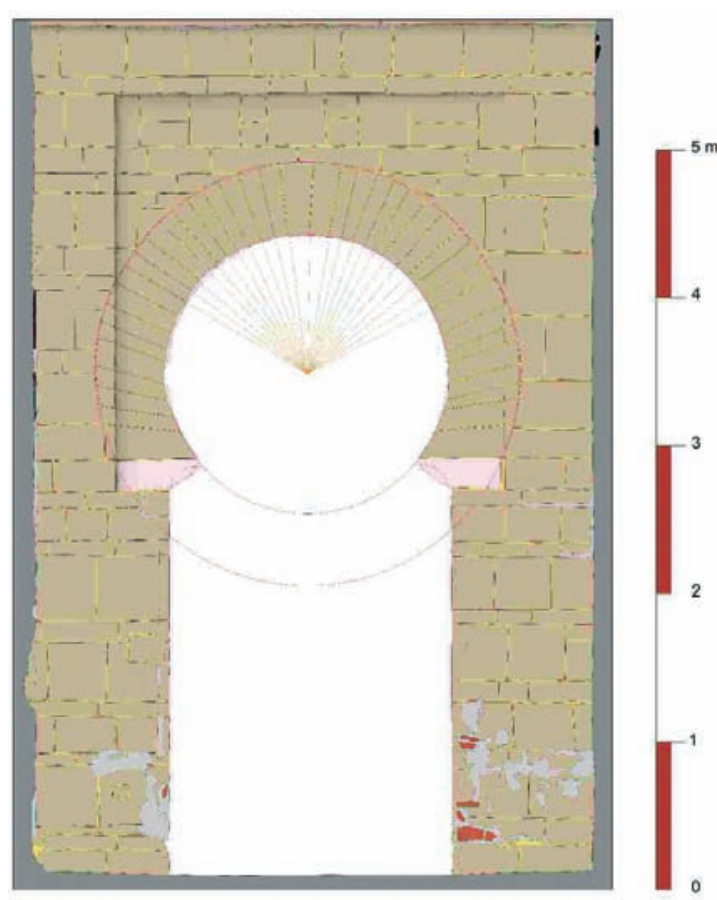

Fig. 25. Alzado fotogramétrico de la puerta principal del Alcázar de Jerez de la Frontera. Aparentemente, el alfiz no se rige por ningún trazado geométrico concreto

se repite con tanta fidelidad en ningún otro recinto almohade (Figs. 27 y 28). No obstante, las reducidas dimensiones de todos los elementos de esta puerta elvense apuntan a que se trate más de un postigo que de una puerta monumental. Considerado ese caso, la propia configuración del acceso redundaría con mayor claridad en su carácter simbólico, al atribuirse a un tipo secundario la fisonomía de uno principal. En este recinto también se erigieron albarranas y poligonales, y se emplearon cajones encintados para erigir lienzos hasta la merlatura.

\section{CONCLUSIONES}

Con este trabajo hemos pretendido incidir en el establecimiento de un lenguaje formal por parte de las autoridades almohades en sus fortificaciones andalusíes. Más allá de una simple estandarización constructiva, que demuestra una indudable madurez de los sistemas de producción en la arquitectura, las pautas seguidas tienden a mostrar un claro mensaje sobre el promotor de la obra en cuestión. De este modo, y como han demostrado estudios recientes de M. ${ }^{\mathrm{a}}$ Antonia Martínez Núñez o Patrice Cressier, ya citados, el afán propagandista y de legitimación de los califas almoha- 


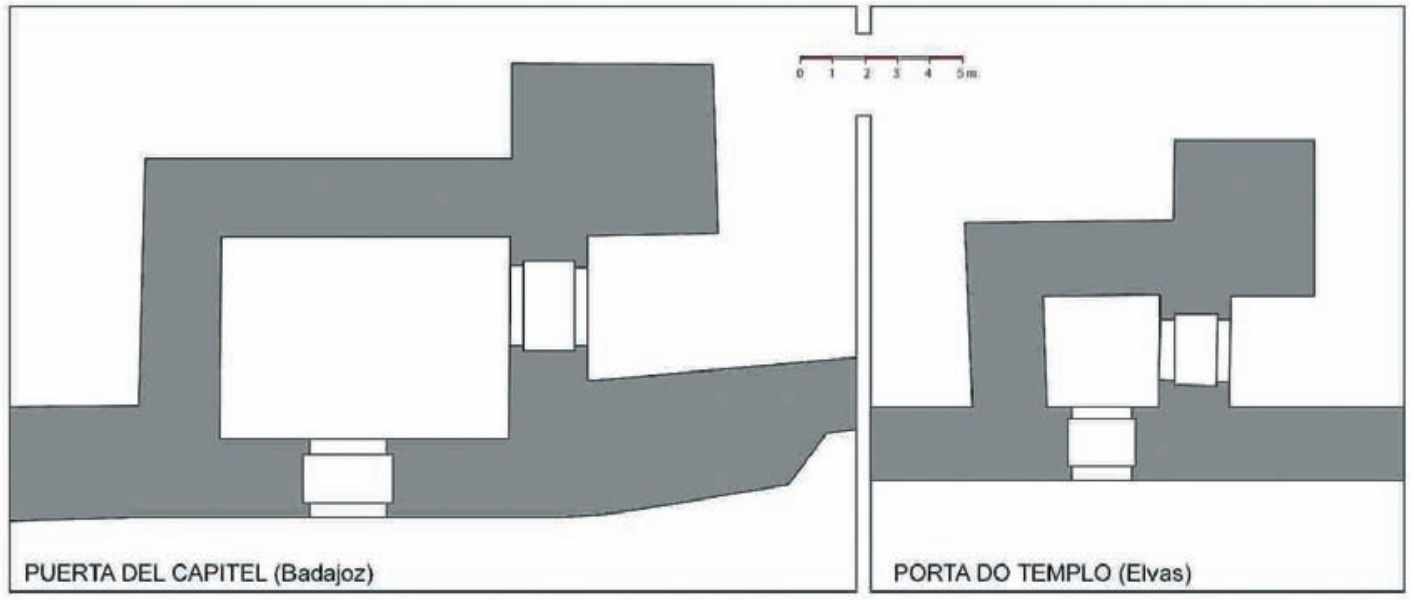

Fig. 27. Plantas de las puertas del Capitel y Templo representadas a una misma escala

des se manifestará en numerosos aspectos de la vida cotidiana: las prácticas religiosas, las acuñaciones monetarias o la propia arquitectura seguirán un lenguaje nuevo y particular. En el caso de las fortificaciones, abundantes como consecuencia de un prolijo programa de defensa del territorio, los nuevos recursos se manifestarán tanto en la propia morfología de las obras como en su forma de ejecutarse.

En los casos que hemos tratado, hemos querido insistir en algunos puntos en especial. Por una parte, los propios cajones de hormigón de cal, tan característicos y pobres, recibirán sobre su superficie cintas y revestimientos de cal que, más allá de ser simples recursos constructivos,

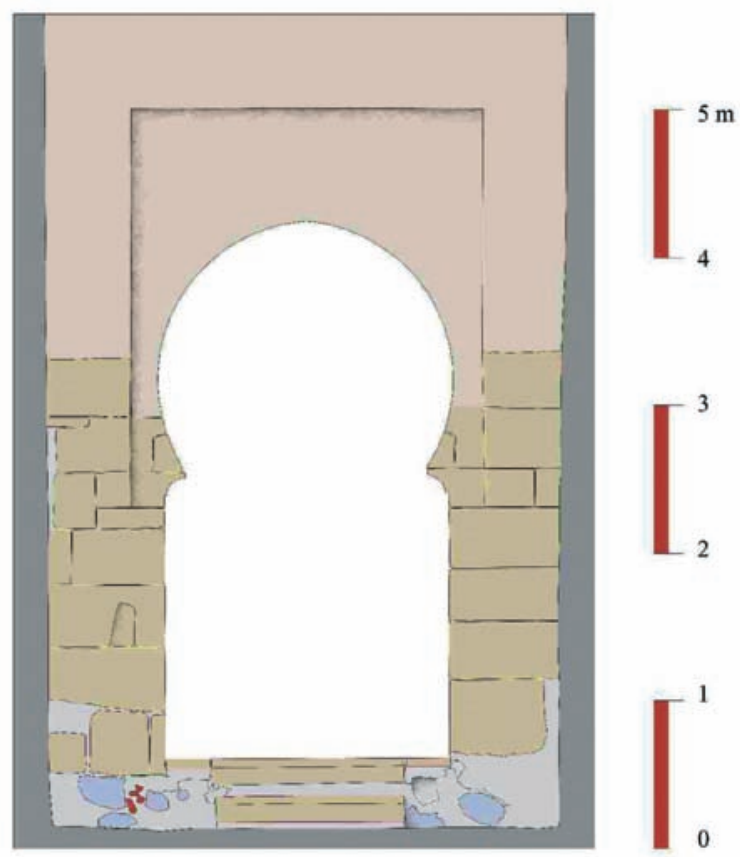

Fig. 28. Alzado fotogramétrico de la fachada exterior del primer arco de la Porta do Templo en Elvas. La parte superior es una hipótesis de la apariencia original, actualmente muy desfigurada por un arco moderno de trazado poco canónico terminarán por adquirir un lenguaje propio y representativo que caracterizará a la obra de tapiería. El ejemplo de la torre de los Pozos de Cáceres, con inclusiones epigráficas en las cintas, será el caso más sorprendente y avanzado de estas prácticas de albañilería.

Por otro lado, hemos incidido en el carácter de las torres albarranas y/o poligonales y, en especial, el de las puertas, como zonas susceptibles de recibir especiales atenciones. Sobre los accesos monumentales se puede concluir que se sigue una línea dispar a la de sus hermanas magrebíes, y en cierto modo, con un cierto ascendente y parentesco con obras de periodos anteriores dadas sus características constructivas y su sobriedad. Sorprende la uniformidad en la ejecución de muchas de ellas, que hace plantearnos la existencia de verdaderos equipos de constructores que son delegados por la autoridad de turno allí donde son necesarios. Los casos de las puertas de Carmona o Badajoz son buen ejemplo de ello. En cualquier caso, la habitual movilidad de los responsables de erigir las construcciones oficiales deja bien a las claras la pujanza del promotor y su capacidad de organizar la ejecución de obras dentro de un vasto programa arquitectónico.

En definitiva, las líneas esbozadas apuntan a una directriz muy evidente en toda la campaña fortificadora que llevan a cabo los almohades en la orilla norte del Estrecho, y los nuevos datos aportados vienen a confirmar esa línea apuntada en otros estudios acerca de la normalización de las obras ejecutadas. La carga de propaganda que subyace detrás de este lenguaje oficial es evidente, y viene a confirmar a los alarifes Unitarios como los responsables del más ambicioso y planificado programa de obras militares de la historia de al-Andalus.

Recibido: 15 de septiembre de 2008 Aceptado: 13 de enero de 2009 